University of Louisville

ThinkIR: The University of Louisville's Institutional Repository

Electronic Theses and Dissertations

$12-2020$

\title{
"Don't put an 'or' where God puts an 'and"': constitutive rhetoric in queer Appalachia.
}

Brooke Elizabeth Boling

University of Louisville

Follow this and additional works at: https://ir.library.louisville.edu/etd

Part of the Rhetoric and Composition Commons

\section{Recommended Citation}

Boling, Brooke Elizabeth, "'Don't put an 'or' where God puts an 'and'": constitutive rhetoric in queer Appalachia." (2020). Electronic Theses and Dissertations. Paper 3528.

https://doi.org/10.18297/etd/3528

This Master's Thesis is brought to you for free and open access by ThinkIR: The University of Louisville's Institutional Repository. It has been accepted for inclusion in Electronic Theses and Dissertations by an authorized administrator of ThinkIR: The University of Louisville's Institutional Repository. This title appears here courtesy of the author, who has retained all other copyrights. For more information, please contact thinkir@louisville.edu. 
"DON'T PUT AN OR WHERE GOD PUTS AN AND:" CONSTITUTIVE RHETORIC IN QUEER APPALACHIA

\author{
By \\ Brooke Elizabeth Boling \\ B.A., Johnson University, 2018 \\ M.A., University of Louisville, 2020

\begin{abstract}
A Thesis
Submitted to the Faculty of the

College of Arts and Sciences of the University of Louisville

In Partial Fulfillment of the Requirements

for the Degree of
\end{abstract}

Master of Arts in English

Department of English

University of Louisville

Louisville, Kentucky

December 2020 

"DON'T PUT AN OR WHERE GOD PUTS AN AND:" CONSTITUTIVE RHETORIC IN QUEER APPALACHIA

By

Brooke Elizabeth Boling

B.A., Johnson University, 2018

M.A., University of Louisville, 2020

A Thesis Approved on

November 17, 2020

by the following Thesis Committee:

Thesis Director
Dr. Karen Kopelson

Second Committee Member

Dr. Amy Clukey

Third Committee Member

Dr. Catherine Fosl 


\section{TABLE OF CONTENTS}

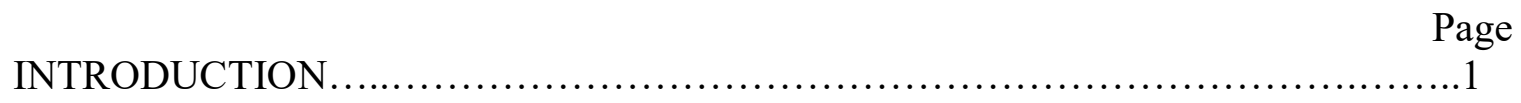

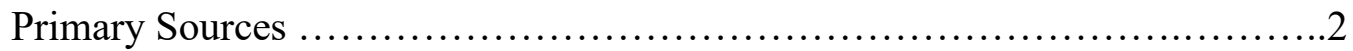

Theoretical Framework: Constitutive Rhetoric ............................. 3

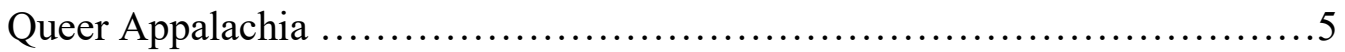

Queer Appalachian Visibility/Identity ...................................

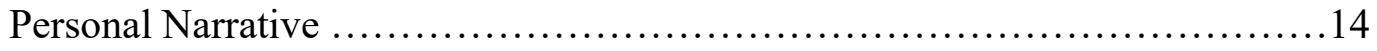

CHAPTER ONE: ELECTRIC DIRT ............................................ 18

Electric Dirt and Appalachian Identification ............................ 18

Anti-Capitalism in Electric Dirt ......................................23

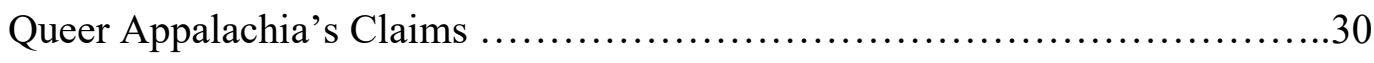

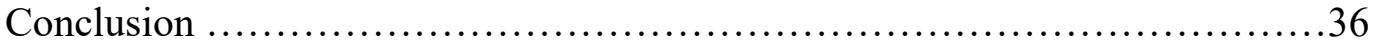

CHAPTER TWO: @QUEERAPPALACHIA ......................................... 37

Social Networking and Constitutive Rhetoric.............................39

Constitutive Rhetoric in @QueerAppalachia .................................43

Success and Failure of Queer Appalachia's Rhetoric .......................51

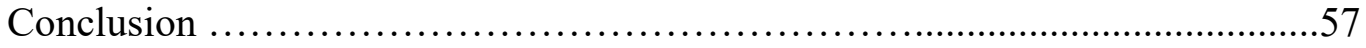

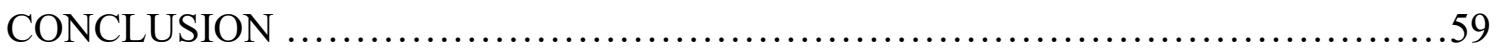

REFERENCES......................................................... 64

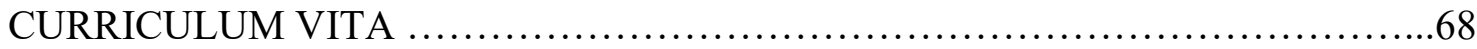




\section{INTRODUCTION}

Appalachians who use the word "queer" to specifically refer to being gay, lesbian, bisexual, transgender, queer, intersex, and/or asexual, are regularly faced with negotiating how these parts of their identity can exist simultaneously, as many both within and without the region believe it is impossible to be Appalachian and queer at the same time ${ }^{1}$. Despite rampant homophobia in the region and external narratives suggesting that queer Appalachians do not exist, these folkx ${ }^{2}$ have carved out spaces for themselves to assert their identities and create community and belonging through rhetorical actions. Many of these spaces are online, taking place through digital media and social networking platforms. The self-described "artist collective" known as Queer Appalachia has helped in creating a digital safe space for Appalachian youth who identify as queer while advocating for anti-capitalist political goals and working to coalesce for national action and change. Queer Appalachia's website states, "we survive and even thrive through sharing tales of wildcrafting our queerness, foraging for pieces of ourselves within the intersections of coal mines and class, race and religion, food justice and colonialism." Queer Appalachia works to recruit an audience that is aware of and working against the intentional and inherent injustice present in the region as a whole, arguing that this injustice is rooted in capitalism and must therefore be combated with a class-oriented,

\footnotetext{
${ }^{1}$ Due to the fact that many Appalachians use the word "queer" to specifically refer to being gay, lesbian, bisexual, transgender, queer, intersex, and/or asexual, I use "queer" in the same way throughout this project. I intend the use of "queer" not to refer to "non-normativity," but specifically non-heterosexual identities.

2 "Folkx" is a term of address used by rural activists as inclusive terminology to refer to an audience containing individuals with queer sexualities and gender identities.
} 
anti-capitalist approach. In this project, I use a framework of constitutive rhetorical theory (elaborated below) to analyze Queer Appalachia's social media presence and the 'zine published by the collective in order to argue that QA's social media works to interpellate subjects into an identity that can do anti-capitalist social justice work. This introduction serves to outline the history of my primary texts, map the framework of constitutive rhetoric, tell my own story and stake in the argument, and frame out the analysis I execute in the following chapters.

\section{Primary Sources}

The primary texts I examine in this project are the volume 1 of the 'zine published by this group titled Electric Dirt, as well as the Instagram page of the group Queer Appalachia. In order to provide context for Queer Appalachia, I also examine their website, which serves as a centralized hub of social media accounts and publications. The Instagram page serves multiple functions: first, to provide an intersectional, safe community by and for queer Appalachians; second, to raise awareness on important issues, provide resources, and coalesce to take action; third, to request and showcase submissions for the Electric Dirt 'zine; and finally, to project the existence of progressive Appalachians to a mainstream audience. All of these goals work together to form an online intersectional activist community.

Queer Appalachia called for submissions in 2016 for volume one of Electric Dirt in the following way via Instagram: "WANTED: everything \& everyone ever. All art \& Visual Art; field notes, poems, prose, essays, playlists, reviews, photography, crosswords, word searches, articles, sketches, collages, paintings, comics, list, and anything else as long as it has to do with Queer Appalachia/Queer South” (@queerappalachia 29 July 
'16). According to QA's website, the collective itself began with the late Bryn Kelly, an Appalachian trans woman, who had a dream of publishing a 'zine centered on queer Appalachians. Because this collective truly began with the publication of the 'zine, I am examining Electric Dirt as an integral stepping stone, not the finale, of the Queer Appalachia collective: a stepping stone that jump-started the Instagram account that has become a digital haven for and activist platform by so many queer Appalachians. Through constructing and publishing Electric Dirt volume 1, Queer Appalachia became a collective focused on political action through art and resistance. It realized the vision of the movement's late founder before motivating a movement that has made significant change in the region.

\section{Theoretical Framework: Constitutive Rhetoric}

Constitutive rhetoric is a rhetorical theory developed by Maurice Charland in 1987 in his essay titled "Constitutive Rhetoric: The Case of the Peuple Québécois." Constitutive rhetoric utilizes the theories of Burke, Althusser, and Derrida to formulate an understanding of the role of the "hailing" power of language in relation to audience. Using a document declaring sovereignty by French-Canadian residents of Quebec, Charland argues that constitutive rhetoric calls its audience into being. According to Charland's theory, audience members are participants in the rhetorical transaction rather than an "extrarhetorical" factor, or simply the recipients of the persuasive elements of rhetorical address. The audience is an interpellated subject in Althusserian terms rather than "a transcendent subject as audience member, who would exist prior to and apart from the speech to be judged" (Charland 133). Charland continues, "Interpellation occurs at the very moment one enters into a rhetorical situation, that is, as soon as an individual 
recognizes and acknowledges being addressed. An interpellated subject participates in the discourse that addresses him" (138). A key element of interpellation is the existence of the individual who possesses an identity as a subject, because, according to Althusser, each individual is hailed into subjectivity at birth, and constitutive rhetoric further interpellates these subjects into the rhetorical address as the audience.

The theory of constitutive rhetoric, however, presents a paradox that Charland recognizes. He states that the audience as subject possesses "character, nature, or essence," which is because "this identity defines inherent motives and interests that a rhetoric can appeal to" (137). However, Charland recognizes that "rhetorical theory's privileging of an audience's freedom to judge is problematic, for it assumes that audiences, with their prejudices, interests, and motives, are given and so extra-rhetorical" (133). Rather than offering a solution to this paradox, however, Charland states: the ideological 'trick' of such a rhetoric is that it presents that which is most rhetorical, the existence of...a subject, as extrarhetorical. These members of the [people] whose supposed essence demands action do not exist in nature, but only within a discursively constituted history. Thus, this rhetoric paradoxically must constitute the identity....as it simultaneously presumes it to be pregiven and natural, existing outside of rhetoric and forming the basis for a rhetorical address" (137). The fundamental complexity of constitutive rhetoric, then, lies within the construction of identity. According to Charland in "Constitutive Rhetoric," "As a theory, constitutive rhetoric accounts for the process of identity formation that this genre depends upon, where audiences are called upon to materialize through their actions an identity ascribed to them" (616). Charland continues, stating, "identity itself can be seen as rhetorically 
produced rather than a given that is prior to persuasion and upon which persuasion depends" (617). Charland describes "identity" as collective rather than individual, which resolves the paradox as such: constitutive rhetoric creates a collective identity as the addressed audience, interpellating individuals into this collective identity based on their existing subjectivities and situating them in a historical context, providing the proper situation for action and subversion ${ }^{3}$. As I further explain in this introduction, the Queer Appalachia collective is one such example of an identity created through constitutive rhetoric.

\section{Queer Appalachia}

Since the early twentieth century, the field of Appalachian studies has flourished, with scholarship focusing on topics such as environmentalism, racism, regionalism, literature, rhetoric, cultural studies, feminism, and many others. Much of the scholarship done regarding Appalachia has been published in the Journal of Appalachian Studies, run by the Appalachian Studies Association (ASA). The Appalachian Studies Association originated in long held traditions of activism and scholarship present among current and past residents of the region. Much of Appalachian scholarship has had an underlying focus on undoing stereotypes and remaking specific associations held about Appalachia

\footnotetext{
${ }^{3}$ Rhetoric scholars have built on Charland's foundational theory to theorize the constitution of multiple identities, including southern Black identity in cooking discourses (Medhurst), Indigenous identity under President Obama (Glenn), white women's citizenship (Palczewski), Evangelical Christian identity and race (Hill), lesbian and feminist identity through resistance (Samek), South Asian American discourses (Mudambi), Southern identity and food (Atkins-Sayre et al), Black feminist identity and agency (Vanderhaagen), the Young Lords activism and Latinx identity (Enck-Wanzer), queer identity and counterpublics (Dunn), French Muslim identity and linguistics (Croucher), antebellum African-American identity (Jasinski), white lesbian feminism (Tate), Southern feminism (Stokes), Cuban identity under Obama (Kice), African motherhood (Prasch), and others. Of primary importance to my analysis is Warnick and Heinemann's theory of constitutive rhetoric and identity in digital spaces, which I discuss in chapter one, and Karen Kopelson's argument about the constitution of subjects as recruitable in her examination of the supporters of certain environmental breast cancer organizations, which I discuss in chapter two.
} 
in mainstream culture. However, although Appalachian scholars have been examining the intersections between queer identity and Appalachian identity since the 1990s, less attention has been paid to questions of queerness when compared to other issues. In the Journal of Appalachian Studies, the first article explicitly examining Appalachian queerness was published in 1995. Scholars like Mary Anglin examined queerness in conjunction with issues like HIV/AIDS, a connection also made by other writers like Jeffrey Fleishman, revealing the beliefs of the region that "Appalachians with AIDS are presented predominantly as gay men and therefore as outsiders" (Anglin 173). Although Anglin worked to dispel this particular myth regarding HIV/AIDS, violence and discrimination against queer folks in Appalachia persists. Queer Appalachians often believe that invisibility is safer, and so a prominent theme throughout articles looking at queerness is that of invisibility. Jeff Mann illustrates the centrality of safety in his response to Silas House's 2014 ASA keynote speech, stating, "bias hasn't disappeared, so it takes more subtle forms. A minority you can no longer run out of town, you can ignore and tacitly dismiss. To borrow a powerful word from House's address, you can make members of that minority feel invisible. There is sometimes a vast chasm between speaking and being heard" (130). The chasm between speaking and being heard is one that Queer Appalachia works to bridge by constituting a large audience of those both inside and outside of the region to spread awareness about regional issues.

Mann's 2014 essay echoes sentiments he presented in an earlier 1999 essay, which was also concerned with invisibility: "Militant AIDS-activist groups have a slogan: Silence $=$ Death. For gay small-town and rural residents, most often Invisibility $=$ Survival" (211). This invisibility proves to be a difficult thing to manage. Queer 
Appalachian writers from the 1990s until the present have focused on the "mass exodus" of queer folks from Appalachia to urban locations. Mann, and many others, however, have found it impossible to abandon their Appalachian heritage, instead striking a kind of balance between protecting themselves and embracing their dual identities. Queer people are the "Other" in Appalachia, a region that is itself "Othered" in relation to America as a whole, a reality that House addressed, stating, "We are a New Appalachia made up of a people who are perpetual immigrants, those whom the rest of the nation see as the Other, no matter how assimilated they may be within this culture" (104). House goes on to mention the mass exodus of Appalachian youth, a problem which Rachel Garringer, the founder of the Country Queers project, ${ }^{4}$ also addresses, simultaneously contrasting it with the widely publicized homophobic murders of Brandon Teena and Matthew Shephard, "which, until very recently, have served as some of the only accessible evidence of rural queer existence" (80). Garringer believed, like many other queer Appalachians, that "I could not have my queerness and my mountains, too, that I would not be safe there, that I would not be able to survive, much less thrive" (80). Because of this invisibility, Appalachian scholars' focus has been on illuminating the queer experience of Appalachians. Queerness in Appalachia is a complex and divisive issue, but by speaking out, marginalized voices are working to constitute a collective whose members possess these identities, creating spaces where it is safe to be both Appalachian and queer in order to use the visibility and safety of those spaces to organize for community and national change.

\footnotetext{
${ }^{4}$ Though I am not examining the Country Queers project in detail, it is another coalition formed for queer Appalachians to share their unique stories.
} 


\section{Queer Appalachian Visibility/Identity}

Though invisibility as a survival mechanism is, as I have mentioned, a common theme throughout the work of Appalachian studies scholars writing about being queer in the region, much of Appalachian scholarship works to unify the social issues present in the region with the rest of the nation, acknowledging that regional problems are America's problems. Silas House exemplifies the importance of unifying the issues present in the region with those of the entire nation when he states, "Homophobia lurks in the hollers, and slithers along the ridges of Appalachia. The reason why is because Appalachia is in America. What is happening here is happening throughout the rest of the country. Even though change is happening, even though great progress is being made on gay rights, we are still a nation that cannot rectify 'the gay problem'” (110). Jeff Mann concurs, stating, "Silas House is unquestionably correct: hate crimes occur in Appalachia, and all over America. The 'summer of hate' he mentions is hardly anomalous. I've been spared, for the most part. (It helps to be big, angry, bushy-bearded, and gendernormative) ...Many of my queer compatriots have not been as lucky as I've been. Some lives have been shattered. Some lives have been ended" (128). Here, Mann cuts to the heart of the fundamental difficulty of being queer in America—being visible. Being invisible, or passing as straight, will result in a much greater sense of safety than otherwise. Embodying queerness in Appalachia is dangerous, just as embodying queerness anywhere else in the country is as well. For example, from 2018 to 2019, the Human Rights Campaign confirmed that, at minimum, 52 trans women were murdered in the United States. A rash of anti-LGBTQ bills were proposed across the country in February 2020, and Tennessee passed a law in January 2020 restricting same-sex couples 
from adopting.

For the purposes of examining@QueerAppalachia's rhetorical actions, it is important to include the words and experiences of actual queer Appalachians to identify that members of the @queerAppalachia coalition are actively living out their queerness in a visible way for activist purposes and to show their identity as constituted into a queer Appalachian subjectivity through material action. To show how queer Appalachians discuss their own identities, I utilize the interviews done and conclusions drawn by Katy Ross in their communication dissertation titled At the Intersection of Queer and Appalachia(n): Negotiating Identity and Social Support. In their dissertation, Katy Ross interviewed queer individuals from rural Appalachia, identifying several particular factors of experience that caused queer Appalachians to remain in the region. The most relevant to this project is the factor of "possessing altruism." Ross defines altruism, stating, "just over half of the interviewees indicated that feelings of altruism were a decision factor in their identity negotiations. [Participants] were more likely to publicly negotiate their queer identity if they had an altruistic motivation. Altruism, or an intrinsic motive, includes "the desire to help others or create a better society"' (91). Appalachians identifying as queer, then, are motivated to remain in the region in order to enact specific political goals of bettering the region they call home. Ross continues, quoting one of their participants: "Specific to place, Mister described his eagerness to preserve a queer presence in Appalachia, 'I want to make it a reality that people can stay here and come back here. Because it is home. And if we keep continuing to leave, the older generations are going to die off and then what's left?"' (93). I quote Ross extensively here because their research and interviews identify a key aspect of @QueerAppalachia’s work: staying 
in the region as a queer person is, itself, a rhetorical political action. The members of the coalition are choosing to visibly embody their queerness in a way that, although possibly rife with social repercussions and/or danger, highlights the intersectionality of injustices that need to be addressed in the region, which queer Appalachian folks are uniquely positioned to address.

In addition, Ross's interviews exemplify intersections - and subsequent points of tension and similarity— between the experiences of both being queer and being Appalachian. Regarding the pressure to leave the region, Ross states, "Rural Appalachia was where many co-learners preferred to live and stay, not only because they enjoyed the familiarity, but also to show others that queer individuals could, and did, thrive in these areas” (109). Being Appalachian means many things; as identified by Ross's research, folks from the region shared commonalities in feeling a connection to the land and mountains. As a region, Appalachia is tightly knit, sharing positive cultural values, experiences, and familial ties. Another participant in Ross's study stated, “[Being Appalachian] is more rural and cultural based, rather than a southern lifestyle. I feel like it has a lot [of] ties with music and [binary] gender roles...You identify with the mountains and the wilderness and being outside" (116). This emphasis on binary gender roles is one example of an element of Appalachian identity that progressive rural folkx struggle to navigate. In another example of Appalachian identity, Ross identified that many from the region were aware of their accents when speaking. The Appalachian accent is unique to the region; it is similar to a Southern drawl, but with many significant differences that are particular to the mountains. Although accents can distinguish native status in the region, many of Ross's participants intentionally diminished their accent, 
reducing the visibility of their Appalachian identity in order to "pass." This tendency to choose whether to amplify or reduce elements of Appalachian identity bears incredible similarities to many queer folks' choice regarding working to "pass." Appalachian identity is as complex and personal as any identity marker and visible intersections with queerness can provide opportunities for activism, as evidenced by the work of @QueerAppalachia.

Part of Appalachian identity is being part of a long history of class struggle. House provides an example of the impact of outsider exploitation stemming from a long history of extractive industry in the region in a 2016 article, stating, " 2.5 million dollars of the coal tax severance went to fund renovations to Rupp Arena in Lexington in 2013 while coal towns in Eastern Kentucky struggle to stay alive and are told the state doesn't have enough money to fund projects there" (67). House further offers an excellent view of how Appalachian scholars conceptualize the capitalist nature of the region's exploitation:

I will say that I do blame a lot of our problems on the coal industry and their endless manipulation and victimization of an entire people and place. I do blame our politicians for not representing us properly... I blame the media for one hundred years of portraying us as stupid, violent, oversexualized villains in movies that go back to the beginnings of cinema. I blame the media for not offering historical and cultural context. But I have to say that, although I know this is not the popular thing to say, some of the blame rests upon our own shoulders. We have to get on that "road back" that Jim Wayne Miller wrote about in 'Brier Sermon,' and take control of our own place and our own identity. We have to take the wheel. We have to take 
hold of the lever in the voting booth. We have to regain the pride we have always had, and harness that power (68).

This quote illustrates the desire and awareness that Appalachian folks have regarding their disenfranchisement. Although, and perhaps because, much of the abuse and exploited labor suffered by the region has come from external sources and the extraction industry in Appalachia, folks in the region are, contrary to many popular narratives, motivated to enact change and help the region themselves through anti-capitalist work, and organizing into coalitions has historically proven to benefit the region more than outside help.

This framework of enacting change from within is a framework of mutual aid rather than potentially colonizing and capitalistic non-profits that do not represent the needs of the region. @QueerAppalachia addresses the motivation for mutual aid on their website: "It is our intention that Queer Appalachia not add to the region's blooming nonprofit burden. Billions of dollars come into Appalachia in the form of grants and endowments to fund the work of nonprofits. Comparing the funding coming into the area and the services which are provided, the nonprofit structure which is supposed to serve the community can feel just as criminal as the coal industry." @QueerAppalachia’s impetus at every turn is evident: Appalachians working to better their own region from within using a framework of mutual aid and anti-capitalism. Contrary to narratives pushed by outsiders like J.D. Vance, who wrote the problematic and widely discredited pseudo-memoir Hillbilly Elegy that effectively usurped and colonized the voices and experiences of real Appalachians in mainstream discourse, Appalachian injustices are much more complex than "work harder." Rather, Appalachian disparity has been created 
through centuries of capitalist exploitation, systemic racism, environmental abuse, and many other intersecting problems that only folks from within the region can truly understand.@QueerAppalachia addresses these injustices throughout its social media pages, on its website, and through Electric Dirt:

Queer Appalachia is an artist collective. Anyone is welcome at our table regardless of addiction status, mental health, socioeconomic status, identity, race or how 'out' you are. When we use hashtags like \#nooneisdisposable, it's not marketing or branding. We invite anyone to work along side us. For far too long, depictions of these regions have been white-washed and have made invisible the communities of color that live and struggle alongside us. We acknowledge the necessity for our work to not emulate these patterns and seek that both the project and its contributors accurately and appropriately reflect our diverse community."

At this point, I feel it important to address my own heritage and stake in this project, as although Appalachian scholarship aims to unify with rather than divide from the rest of the nation, I believe it is still important to privilege narratives about the region from those who do claim Appalachian identity, particularly when considering the history of unfair treatment by outsider analyses as noted by @QueerAppalachia and other Appalachian scholars. I argue that privileging these narratives will lead to more fruitful coalition building with those outside of the region, as these lived experiences work to contradict years of stereotyping of those from Appalachia.

\section{Personal Narrative}

I was born in Eastern Kentucky to a family whose history is steeped in poverty and disenfranchisement. My maternal family has been in the region for as far back as we 
can figure. My maternal grandfather—Papaw, we called him—worked as a stone mason in Rockcastle County, Kentucky for his entire life, beginning a business that my mother helped run for much of her young adult life, until she met my father and became pregnant with me. My mother was the first in her family to attend college and moved to the urban city of Louisville with me and my siblings when I was 6 years old, participating in the Appalachian diaspora as displaced "country folk." We returned to "the old homestead" incredibly often, and I always told my Mamaw that, when I grew up, I wanted to "move back home." My own Appalachian heritage and identity has never been in doubt to me; I have always taken it for granted, despite the fact that my mother worked hard to erase her accent (a few stray mispronunciations remain) and I have almost no accent to speak of (until I am around my family, that is). I have often told friends and family that I refuse to move anywhere where I cannot see my Appalachian Mountains-flat terrain makes me thoroughly uncomfortable, as ridiculous as that is in reality. Papaw always called me "his country girl"- - "you can take the girl out of the country, but you can't take the country out of the girl," he'd say when I participated in traditional "country folk" familial activities of shooting at watermelons, husking corn, canning vegetables, and scarfing down homemade sauerkraut (which is eaten cold right out of the jar in the region, by the way).

My extended family does, however, consider my immediate family to be "city slickers" due to our relocation to an urban area. While attending college, I developed political views antithetical to what my family - the people from my "true home"believed. Additionally, during my second year in college, I came to recognize my own queerness. For the first time, I felt wholly alienated from my mountains, my culture, my 
family, and my religion. Without coming out about my sexuality, I cried to my mother that I felt like I had lost a vital part of my identity when I began to clash with my Appalachian family during our habitual late-night theological, philosophical, and political conversations. I questioned how I could keep both parts of my identity, which I saw—and continue to see-as fundamental, but seemed at the time to be diametrically opposed. I wrestled with this reality for the remainder of my undergraduate career, only arriving at a resolution within myself after I began to focus on Appalachian studies during my graduate program at the University of Louisville. Through the academic study of queerness and Appalachian identity, I was able to find a way to unify these parts of my identity within myself-although my family is yet unaware of my own sexual identity. As evidenced by this narrative, my investment in this project is deeply personal, and although I would never, as J.D. Vance presumed, attempt to speak for an entire region, I see my own role with this project as amplifying the voices of those who continue to reside full-time in my homeland. @QueerAppalachia has, with their activism and rhetorical actions, enacted significant and lasting change through their constitution of a progressive rural identity, and I feel as though their work should be examined in an academic context. Appalachia is historically a region of turmoil and disenfranchisement, and @QueerAppalachia's motivation against fatalistic thinking in the region is a comforting and empowering refrain underneath the work I intend to continue doing in my home region.

As one who considers themselves a subject of the intersectional identity "queer Appalachian," and furthermore was interpellated into the Queer Appalachia collective through both my research and my identity, my following examination of the constitutive 
rhetorical practices of the Queer Appalachia collective throughout this project is both personal and political. The collective formed by Queer Appalachia's rhetoric has articulated my identity and joined me with other audience members of this multivocal rhetoric in order to produce change in the region through political, anti-capitalist action and mutual aid. As Charland states, "while classical narratives have an ending, constitutive rhetorics leave the task of narrative closure to their constituted subjects" (143). Queer Appalachians have now a collective identity and a narrative to control, and in the following pages are the theoretical underpinnings of how this formation occurred. In chapter one, I examine the narrative qualities of the Electric Dirt zine and argue that it successfully constitutes an audience that is positioned toward class-based activist work in the region. In chapter two, I argue that the constitutive rhetoric on @QueerAppalachia’s Instagram page continues the work of the audience created by Electric Dirt, but falls short in recruiting those who are not already sympathetic to progressive Appalachian causes by failing to constitute as recruitable those outside this subjectivity. 


\section{CHAPTER ONE: ELECTRIC DIRT}

The Electric Dirt zine was created by members of a community of queer Appalachians, recruited mainly through social media and other digital platforms. The zine is uniquely composed of multiple entries by rural queer folx, ranging from images to short stories to recipes. Electric Dirt was compiled and published by the @QueerAppalachia collective, created by and for rural queer folx across the country, and the submission and publication of these entries as rhetorical actions functions in a way that constitutes an audience. The zine is not the production of a single rhetor; it is a multivocal artifact that brought together a community. Using Maurice Charland's theory of constitutive rhetoric, I examine the way that Electric Dirt constitutes an audience of queer Appalachians. First, as Charland discusses the integral role of narrative in constituting a community, I analyze the narrative presented by Electric Dirt that constitutes a queer Appalachian identity. As part of this analysis, I establish the collective subject constituted by the narrative of Electric Dirt. Second, utilizing my conception of Electric Dirt's constituted subject, I explain the claims made by this identity for political action, which, I argue, rearticulate the conflict between Appalachia and the country at large as a class-based, struggle, specifically an anti-capitalist one, rather than a conflict between politically left and politically right viewpoints. In addition, Electric Dirt constitutes non-queer nonAppalachians into this community by virtue of class-based identification; namely, working class and anti-capitalist identification. Electric Dirt, through presenting a queer Appalachian narrative, constitutes its audience into a positionality aimed at dismantling 
class-based oppression.

\section{Electric Dirt and Appalachian Identification}

Electric Dirt's narrative is created through entries that focus on issues of place, gender, sexuality, race, and other constructed identity categories. The purpose of constructing this narrative is to first, construct a collective, progressive identity for Appalachians that includes folx remaining in the region as well as those who have left in the Appalachian diaspora; second, to recast the division between the region of Appalachia and the rest of the country from one of political differences to what is arguably the true difference, which is rooted in class. Constituting a collective audience is the goal of constitutive rhetoric because a collective subject allows for "an 'ultimate' identification permitting an overcoming or going beyond of divisive individual...interests and concerns" (Charland 139). This 'ultimate identification,' created through narrative, "renders the site of action and experience stable," and therefore, "offer[s] a world in which human agency is possible and acts can be meaningful" (Charland 139). Though the world of narrative is a fictive one according to constitutive rhetoric, as I discuss later, its creation is the first step in constituting a collective subjectivity that can be mobilized to action.

Electric Dirt confronts incorrect perceptions of the region furthered by writers like J.D. Vance, for example, who most recently contributed to political constructions of Appalachia as "Trump country." By casting Appalachia as a place of political, racial, gender, and sexual diversity, Electric Dirt pushes back against the assumptions regarding Appalachia as the place to hold all of America's problems. Because of fatalism toward Appalachia, the region has been resigned to being a "lost cause" in popular thought, a reality which I will expand upon in later sections. In response to liberal America's 
abandonment of the region in both punditry and action, a significant portion of the claims made through the constituted identity in Electric Dirt are to persuade a non-Appalachian audience. This is due to "liberal" America's abandonment of the region in both punditry and action. Progressive national narratives can ignore the problems of Appalachia if they are brought on by its inhabitants' own beliefs rooted in conservatism and bigotry. "Let Appalachia run itself into the ground, and all our problems with it," as it were.

Claims refuting this abandonment are made in Electric Dirt and follow a long history of Appalachian scholars arguing against this phenomena. The formation of the Appalachian Studies Association (ASA) as mentioned in my introduction is one such occurrence, as scholars from the region created a space for discussing issues central to the region and, through that scholarship, worked to combat mainstream narratives implicitly arguing for the desertion of the region. Another organization working against these misconceptions is Appalshop. Originating in 1969 as a community film workshop, one of Appalshop's most important goals, as stated on their website, was to "offer a counternarrative to the one that made Eastern Kentucky the poster child for American poverty." Appalshop celebrated 50 years of success in uplifting folx from the region to tell Appalachian stories and challenge stereotypes. Additional recent publications that continue this work include Walk Till the Dogs Get Mean (2015), LGBTQ Fiction and Poetry from Appalachia (2019), and Appalachian Reckoning (2019). Electric Dirt follows in this canon, creating a new narrative for queer and progressive Appalachians and establishing a space for their stories to be told. Electric Dirt makes a few significant departures from this canon, however, through emphasizing the role of audience, using digital media and multimodality, embracing elements of mainstream queer culture like 
camp and kitsch, and intentionally centering experiences of joy and success in the region, choosing to include but not foreground pain, which is a shift from much of the canonical scholarship and writing about queerness in the region.

Though the nature of regional identity lends itself to considering place as vitally important, those within a queer subjectivity feel displaced in a region as overwhelmingly conservative as Appalachia. Many queer folx, allies, and progressives leave the region in what has been termed the "Appalachian diaspora," while others remain in the region in both conflict and harmony with their own identities. Electric Dirt's narrative, then, is also constructed to provide a history and an ethnography for Appalachians both in and out of the region, unifying those who identify with the region whether they continue to reside there or not. According to Charland, "the distinct acts and events in a narrative become linked through identification arising from the narrative form. Narratives lead us to construct and fill in coherent unified subjects out of temporally and spatially separate events" (139). Therefore, constructing this narrative for Appalachians plays a vital role in creating a collective subjectivity.

I now intend to discuss the two purposes of Electric Dirt's narrative in accordance with Charland's order of the ideological effects of narrative, beginning with the narrative constructed for an Appalachian audience which constituted a queer Appalachian subjectivity. The "story" constructed here by Electric Dirt reveals that, historically, queer folx do and have lived in the region and been subjected to erasure, prejudice, and bigotry, but have retained their Appalachian identities, whether remaining in the region or participating in the diaspora. As Charland argues, "to tell the story of the $[\text { peuple }]^{5}$ is

\footnotetext{
${ }^{5}$ Charland is discussing the Quebecois as a people; therefore, for my purposes, this sentence could also be read as "to tell the story of the people is implicitly..." etc.
} 
implicitly to assert the existence of a collective subject, the protagonist of the historical drama, who experiences, suffers, and acts" (139). One entry, titled "Last Gospel of the Pagan Babies,” discusses the queer community in Lexington, Kentucky during the civil war through an interview with a documentarian. The interviewer, Paul Brown, states, at one point, "I also remember thinking about how refreshing it was that the story of queer folk who were not living in a metropolitan area like New York or LA was being told and celebrated. As someone who grew up in semi-rural Kentucky, I spent a lot of my youth not knowing that there had been such a vibrant queer community that had come before me" (83). Elsewhere in the interview, the documentarian, Jean Donohue, discusses the urgency she felt to preserve the history of queer rural folx who found a haven in Lexington. She states, "context is important here, and not simple. First, Kentucky is consistently perceived by the larger culture to be flatly ignorant, loathsome red state that consistently votes against its own interest: we're seen as a racist, bible thumping intolerant religious state...it's particularly important for young people in the early stages of identifying as LGBQT [sic] not to feel alone, to know they are supported, and that there are many people who came before them who had, and are having rich, happy lives" (85; 87). Here, Donohue brings Appalachia's national reputation into consideration when discussing her impetus for recording queer rural histories in her documentary. Often, queer folx from rural spaces are only 'allowed' to speak of their experiences after they 'escape' the region. Electric Dirt reveals a narrative of folx who are both queer and Appalachian, constructing a new collective subjectivity. This subjectivity is key because, as Charland states, "narrative renders the world of events understandable with respect to a transcendental collective interest that negates individual interest," allowing for the kind 
of community building oriented toward action seen through the Queer Appalachia coalition (139). By constructing this subjectivity, individual problems present in varying factions of those who are working to better the region can be smoothed over for a greater good.

Another example of constructing queer Appalachian history through Electric Dirt's narrative comes from an essay written by Nikki Cooper titled "The Queer Trans Muslim Experience in Appalachia. In this Electric Dirt entry, Cooper states, "I never knew what [my culture] was called for years until someone pointed out that our area is considered Appalachia and that the culture I always assumed was just white weirdness was actually a colorful history of blackness, working class solidarity, invasions by confederate sympathizers, radical left wing movements and anarchists that didn't take kindly to police" (32). Cooper provides an excellent example of those who experience the realities of being people of color, queer, and Appalachian, and still assume that the region was built on "white weirdness." Electric Dirt provides a sorely needed narrative for folx who are unaware of the region's heritage beyond the whitewashed narratives provided by popular media, stereotypes, and J.D. Vance. Cooper addresses these stereotypes later in her essay, stating, "Now Maybe not all but half yall I'd reckon imagine the very same stereotype we all fight everyday and its because even you, my enlightened readers have let this idea prevail" (33). Cooper continues:

We are a diverse people, Appalachian history is filled and has its origins in blackness. I want you to read about the stories of slave owners who make accounts of seeing fiddles and banjos being played by black folks as early as the 1700 century in the mountains I want yall to erase the image of toothless white guy as what 
Appalachia is, we need a better Appalachia, one where you see people that look like me being part of this awesome and culture world" (33).

Though the "reality" of Appalachian heritage as it is constructed in this entry is rooted in blackness and working-class solidarity, previous narratives offered about Appalachia have effectively constructed it as homogenously white, furthermore adding whichever "evil" is perceived to be the country's largest problem on top of that construction.

Elizabeth Catte, for example, states, "our current moment...fetishizes the presumed homogeneity and cohesiveness of the region and uses those characteristics to explain complex political and social realities" (15). Electric Dirt offers an alternative narrative through its collective entries to combat this perception of homogeneity, one that promotes the historical diversity of Appalachia and, as we will see later, positions its audience for political action based on this history.

\section{Anti-Capitalism in Electric Dirt}

Another key component of Electric Dirt's narrative is the anti-capitalist sentiment woven throughout the entries. In Appalachia, known colloquially as 'coal country,' capitalism has ravaged the physical and social landscape in a way unique to the region. This anticapitalist resolve begins as early as the introduction to the zine, when the Queer Appalachia collective writes, "instead of selling ad space and furthering capitalism, we are able to use that space to tell you about the Appalachian Prison Book Project, the Appalachian Feminist Association and the West Virginia Mine Wars Museum, and several others" (4). This statement reveals how deeply rooted are anti-capitalist beliefs in this construction of an Appalachian identity, as not only do the experiences detailed by the entries reject the capitalist influences of outside narratives as well as condemn the 
capitalism that has decimated the region, but even the space used for advertisements is of an anti-capitalist nature. Anti-capitalism contrasts sharply with opposing narratives of "Trumpalachia," as Trump has viciously condemned economic systems other than capitalism and urged his supporters to do the same. Included in Electric Dirt is an interview with Bianca Spriggs, the former managing editor of Pluck, an Appalachian literary magazine. Spriggs's interviewer asks, "the South and Appalachia has always been political, but since 2015 it seems to be extra. The entire world seems to associate the area with Trump supporters...do you feel like these regions are in the trenches of the cultural war?" (7). Spriggs responds, "I'm going into the trenches. That's where people obviously need to see these narratives rerouted and reoriented the most" (8). This conversation exposes two things. First, Spriggs echoes Ross's theory of queer Appalachian altruism, which I examined in the introduction of this paper, as those who remain in the region have a specific agenda and purpose for remaining there. Second, Spriggs's statement exemplifies the explicit focus on "narrative" throughout the zine, examining how crucial it is for a "people" to have a narrative and the power storytelling possesses. Charland refers to this narrative power, stating, "in the telling of the story of a peuple $^{6}$, a peuple comes to be. It is within the formal structure of a narrative history that it is possible to conceive of a set of individuals as if they were but one" (140). A particular aspect of this narrative is anti-capitalism, as additional examples from entries will show.

Electric Dirt provides many different experiences of lived anti-capitalist sentiment, which has the effect of countering Trump's belief that other economic realities

\footnotetext{
${ }^{6}$ Peuple is used by Charland in his conversation on the peuple Quebecois created by the White Paper. The term is used to refer to "a collective people" and is given in French.
} 
are anti-American. Though Appalachia has experienced significant generational damage because of capitalism, it is still a way of life held tightly by many folx in the region, particularly because of a belief of either eventual success in the system or fatalism about the region as a whole. One example of these different lived experiences is provided by Jasmine Morrell, who gave an interview about their queer and POC-run Appalachian tattoo parlor, providing a particularly fascinating example of how the anti-capitalist particulars of this narrative are negotiated through discussing things like business ownership. Morrell states, "One of the hardest things for me, when opening the business, was the morality around participating in capitalism in this particular way that I've never experienced before and never wanted to be a part of" (27). This is significant for constructing a collective queer Appalachian narrative; though an anti-capitalist identity, queer Appalachian subjectivity does not exclude those who participate and succeed in the system through something like business ownership. Instead, the narrative uplifts those who have found subversive ways to succeed without padding exploitative pockets. Morrell addresses this motive, stating, "the ways to quell feeling like a money cog would be paying it forward, or even back. We try to give back to those that helped us and to the communities that we stand for, believe in, and are a part of. Luckily because that's so intersectional, the opportunities are endless" (27). The narrative reveals a "peuple" who are collectively identified; therefore, including queer POC business owners in this narrative strategically includes those who might have felt excluded. Significantly, queer business owners in the region are uniquely positioned to offer mutual aid to the region without participating in the harmful framework of charity. Including them in the construction of this identity positions queer Appalachian business owners to achieve the 
goals of the coalition.

While there are a myriad of other examples of the pure anti-capitalism of queer Appalachian identity in Electric Dirt, the zine also contains reasoning that highlights why capitalism goes against this class-focused constitution of Appalachian identity. For example, Instagram user @ ruavol states in their brief essay, “I don't see options with any political party. None of them operate with the interest of the people. All of them are capitalism-laced fucks" (161). Here, @ ruavol reveals the true perceived enemy of queer Appalachian identity and history. It is not Trump himself, or the Republican party, or the Democratic party; rather, it is the capitalist framework advanced and supported by every political party that has played such a significant role in decimating the region's land, people, and culture. Carter Sickels's entry, a short story about a trans man returning to Appalachia, contains one paragraph in particular which stands out as a description of the harm done to the land by capitalist, exploitative coal companies:

As he drove southeast, away from the wealth, wooded hills then mountains rose up along the interstate — gasps of beauty in a dying land. Despite the many Friends of Coal bumper stickers and billboards, most people around here no longer worked for the mines-the coal companies shut down their operations after making millions, leaving only the corpses of mountains, shaved and flattened, no trees or forest. Orange acid mine run-off trickled through the streams and fed into creeks."

The history of Appalachia is one of capitalism run rampant, destroying land, people, lives, and livelihoods, before taking its spoils and departing the region, leaving a trail of destruction behind that continues through history to today. Writing a history is vital to a 
constituted identity, as one of the key ideological effects of narrative, according to Charland, is that the constituting of a subject necessitates that this subject is also transhistorical (Charland 140). The exploitation of the region in the past continues to impact individuals in the present, creating this collective transhistorical identity. As Charland states, "time is collapsed as narrative identification occurs," and in Appalachia, the still-identifiable destruction of "place" has led to a disruption of a "people" that can be identified across time (140).

Narratives like Vance's portray Appalachia's problems in a fundamentally misunderstood way, positing that the region's generational poverty and seeming inability to "pull itself up by its bootstraps" as the fault of those who live in the region. The narrative presented by Electric Dirt acknowledges that this generational poverty did not arise in a vacuum, but was intentionally orchestrated by capitalist interests. A poem written by Lucy Parks illustrates this reality, stating, "I tell people in New York that I took Hunters Ed class, And they call me hick, call me stupid, call me sacrifice zone, As if I am all of Appalachia, Deemed sacrificial because, Coal is more important than the people who live there" (79). The "concrete link" - which is the term Charland gives for the relationship between members of a single subjectivity distant from one another in time - constructed between the Appalachia of the past, the coalfields, and the Appalachia of the present, is oppression by capitalist interests and working-class insurrection (140). Constructing the queer Appalachian collective identity in this way is vital for the claims made by the collective. The decimation of the region by capitalism in ways that are still evident today provides the basis for the constituting of an anti-capitalist identity. The collective identity built through the consequences of this destruction has the potential to 
interpellate $^{7}$ those from outside the region who also have anti-capitalist sentiments and identities, creating sympathy and identification from those outside the region. Anticapitalist identity itself has a long history and aligns a queer Appalachian collective identity with other political movements against capitalism, legitimating Electric Dirt's calls to action. Charland argues, "political identity must be an ideological fiction, even though, as McGee correctly notes, this fiction becomes historically material and of consequence as persons live it" (137). The fiction of a coherent, unified narrative for a peuple is still important, however, as "narratives 'make real' coherent subjects. They constitute subjects as they present a particular textual position" (138). The collective subject is inhabited by real people and lived experiences through narrative, but without the collective subject, political action as a united single body is not possible. Therefore, Electric Dirt's presentation of the ways that capitalism has ravaged the region as a single coherent narrative allows for both an identification with that narrative through one's own lived experience and existing subjectivity and a positionality through which to enact change because of that narrative.

The historical lived experience of the region is one of exploitation. Though the examination of the historical facts of Appalachian working-class history is beyond the scope of this paper, I do want to describe a few salient points for the purposes of examining how this constituted collective identity is rooted in lived experience. Elizabeth Catte's book, What You Are Getting Wrong About Appalachia, provides an excellent historical examination of the region. Catte argues, "Coal barons credited their industry with bringing order and harmony to an uncivilized place, but what actually came to the

\footnotetext{
${ }^{7}$ The use of the word "interpellate," for Charland, does not have the same fatalistic deterministic connotations present in Althusser's use of the term.
} 
mountains was a vast system of economic exploitation, facilitated through violence and malice by both outside developers and compliant local elites" (Catte 43). Elsewhere, she states, "I suspect even the most progressive among us have been tempted to lob the phrase [war on coal] at someone clueless about the human cost of their energy. People didn't 'do their best' to keep the nation's lights on; they died" (29). Electric Dirt plays a significant role in bringing the violent, bloody history of coal production in the region and connecting it with the working-class experiences of Appalachians in 2020, who, while most no longer work in mines, continue to work in essential positions of food service and retail and are thereby subjected to the dehumanizing effect of capitalism in these positions.

Electric Dirt works against narratives that construct the region as homogenous, straight, white, and conservative by creating a narrative that illuminates the existence of queer, progressive, anti-capitalist people of color in the region. Narrative's role in Electric Dirt is to "offer a world in which human agency is possible and acts can be meaningful" (Charland 139). Without a collective transhistorical narrative, there can be no "queer Appalachian" identity in the way it is constituted by Electric Dirt. Because the zine provides this narrative, however, a collective subject can be created through text. Though the textual collective subject has limitations, it provides a positionality that can be acted upon politically in lived realities. As Charland notes in his article on Quebec sovereignty, the White Paper (a document released by the Quebec government spelling out the peuple's collective identity and their claims based on that identity) "offers a narrative of Quebec history that renders demands for sovereignty intelligible and reasonable" (138). The constitution of a collective, transhistorical subject, as seen 
through Electric Dirt, allows for a subject previously unable to make claims due to its disparities and lack of cohesion to make rhetorical claims and persuade an audience as to the truth of those claims. In the case of Queer Appalachia, a subjectivity uniting progressive identity and regional identity was not previously constituted as it is in Electric Dirt. This unifying constitution allows for the following claims to be made by the coalition.

\section{Queer Appalachia's Claims}

The key claims made by Electric Dirt by virtue of its constituted identity are as follows. First, "liberal" America can no longer write Appalachia off as a lost cause. If there are queer, progressive, $\mathrm{BIPOC}^{8}$ folx in the region, then it follows that the region is important to the larger liberal American narrative which claims to be working for the betterment of all, but particularly disenfranchised, lives. Appalachian lives have been written off by this larger narrative, and Electric Dirt's claims reveal the disenfranchisement of the region as a whole, particularly queer and progressive folx, and this necessitates inclusion into the larger progressive national narrative. Second, Electric Dirt claims that the fundamental conflict in America at large is not left-leaning politics versus right-leaning politics, which have become heavily moralized and (likely irrevocably) entrenched with religious beliefs, but the working-class versus capitalism. In this way, Electric Dirt reorients the "Trump country" narrative to address those who have rejected left-leaning politics or, as is often the case, politics altogether. Elizabeth Catte makes note of the political fatalism present not only in the region, but in working-class ideology altogether. Trump's rhetoric of "drain the swamp," though hollow, appealed to Americans who felt underrepresented in

\footnotetext{
${ }^{8}$ Black, Indigenous, People of Color
} 
politics due to capitalist dogma; similarly, Electric Dirt and queer Appalachia's call of "no war but class war" makes claims about the fundamental problems in the nation as a whole, serving to not only bring Appalachia into the national narrative, but also include working-class people across the country in liberal political conversations.

The history of Electric Dirt has the power to create a collective identity that is positioned to make the above claims and enact change in lived realities. Charland argues that, although all subjects are always already subjectified through address, "this does not imply...that one's subject position is fixed at the moment one enters language. Indeed, the development of new subject positions, of new constitutive rhetorics, is possible at particular historical moments" (141). I argue that the current historical moment allows for the creation of new positionalities, the subjects of which can then enact this change by working from the constituted identity of "progressive queer Appalachians," bringing rural folx into the national narrative rather than excluding the region from progressive history. Charland continues, "successful new constitutive rhetorics offer new subject positions that resolve, or at least contain, experienced contradictions" (142). The constitutive rhetoric of Electric Dirt does this work through constituting an identity that can be both queer and Appalachian and also offers a subjectivity that has a wide range of possibilities for making claims by virtue of identity. Electric Dirt constitutes a queer Appalachian transhistorical collective subject that can therefore make the claim to both inclusion in national progressive narratives and enacted anti-capitalist change and reparations in the region based on that identity. Though not a contributor of the zine, Elizabeth Catte is still a subject of a progressive Appalachian identity, and therefore her articulation of these claims is helpful to illustrate the methodology of political action by these subjects. Catte 
states:

I will try to build power with likeminded individuals and challenge the institutions that harm us. I won't do that by reaching across political divides that are far more complicated here than you can image [sic]. I'll do it by exercising the basic principles of mutual aid and community defense. The people of Appalachia have never needed empathy; what we need is solidarity, real and true, which comes from understanding that the harm done to me is connected to the harm done to you" (52). Catte supports anti-capitalism here though proclaiming her intention to "challenge the institutions that harm us" as well as her references to mutual aid and community defense, which are anti-capitalist frameworks used to circumvent and undo harm done by capitalist corporate interests in a variety of settings. Similarly, these frameworks are often applied in urban settings, and though often discussed by rural activists, are applicable to people across the nation who have been disenfranchised by rampant capitalism. Queer Appalachian subjectivity leans into this framework of mutual aid and community defense as a methodology of aiding the disenfranchised members of an already 'othered' community that has been subjected to fatalism from within and without. When considering the exploitative history of outsiders claiming to want to better the region, in addition to the strong working-class presence, it becomes clear that battling capitalism in every form is the truest solidarity that can be offered to a queer Appalachian subjectivity. Liberal America has a long history of rejecting Appalachia and its residents, which has perhaps never been more evident than in the conversations had about the region in the wake of Trump's 2016 election. As Catte argues, “for liberal political commentators there were no wealthy donors, white suburban evangelicals, or insular 
Floridian retirees responsible for Trump's victory, only hillbillies" (21). A key element of "Trump country" narratives, Catte argues, occurred because "the voices of Appalachians as experts on their own condition are largely absent in the standard 'Trump country' think piece" (23). Finally, a significant and often overlooked facet of the 2016 election is that, while those who voted in Appalachia did overwhelmingly vote for Trump, the overall voter turnout was nothing short of abysmal. I discuss Catte's findings here at length because it illustrates the fundamental misunderstandings of what happened in the region in 2016. In addition, these assumptions have had the effect of leaving "its audience to assume that Appalachians have not earned the right to belong in the narrative of American progress and are content to doom others to the same exclusion" (Catte 23). Though there is an unquestionable amount of prejudice and bigotry present in the region - as there is in the rest of the country - that undoubtedly underscored the votes of some Appalachians, the reality remains that those in the region have largely given up on the democratic process, believing their stories will never be heard or listened to. Trump contradicted this regional political fatalism in a radical way through his seeming attention to rural, working-class voters with statements like "I love the uneducated" and referring to miners as "my guys" (Catte). It is worth noting that, in the primary election, many Appalachian and rural counties that voted for the democratic candidate and self-described democratic socialist, Bernie Sanders, ultimately went to Trump in the presidential election (Catte). Having said this, however, it is important to note that, overall, "the narrative that attributes Trump's victory to a 'coalition of mostly blue-collar and white working class voters' just doesn't square with election data" (25).

This digression is important to my discussion for a few reasons. First, it is 
important to examine the impetus for creating a queer Appalachian subjectivity in order to fully understand the claims being made by this coalition and argue for their success or failure. Second, woven throughout my argument is a dismantling of mainstream narratives and ideas about the region and its residents, and providing background regarding the most recent election—which thrust the region into the national spotlightis necessary to thoroughly analyze what the queer Appalachia collective says about political action and the best way to enact change. Finally, I argue that the most important claim made by this collective identity is that the conflict between the region and the rest of the nation is not a political one, but a class-based one, calling for working-class revolution rather than a "left-wing" political takeover. Substantive change, for a queer Appalachian subjectivity, looks like dismantling the unjust system that brought the region to the disenfranchised position that it is in and implementing systemic political change that primarily supports the lower class and does not allow business owners to oppress an entire region for the sake of profit.

\section{Conclusion}

Regarding the goals of the peuple Quebecois, Charland states, "if the root cause of the struggle of the peuple is the natural impossibility of the peuple to exist without selfdetermination, control of the state machinery becomes the point of resolution" (144). To appropriate this statement for my own purposes, if the root cause of the struggle of queer Appalachians is the everlasting class struggle between the bourgeois and the proletariat, and furthermore there is a movement against capitalist and progressive interests that they have been intentionally excluded from, queer Appalachians must a) be included in this movement and b) have a significant voice, as their experiences with capitalism have 
resulted in significant damage to their region and identity. National — and therefore regional —issues of poverty, homophobia, racism, sexism, ableism, cissexism, and intolerance as a whole cannot be resolved without first addressing the core of the issue, which is, in queer Appalachia's estimation, capitalism. This anonymous contribution to Electric Dirt exemplifies the reality of many marginalized folx, particularly those in the region who are queer and disabled:

I'm a gender trader in rural Appalachia, I don't trust anyone \& no one trust me. I don't look forward to anything, I have nothing to look forward to just some fresh new hell after another. I live in a town full of empty houses, where there's tons of food, clothing stores and pharmacies, of which I am not worthy. I failed at society and capitalism or at least my body did" (159).

A fundamental tenet of the queer Appalachian narrative is this: individuals can be queer in Appalachia, but nobody can be free in the region as long as they are still chained in the shackles of their capitalist history. As long as drug companies make money off of the opioid epidemic; giant conglomerates make money off of retail workers (through a pandemic, no less); companies support Trump's anti-LGBTQIA+ policies but participate in rainbow capitalism; landlords profit off of folx living in generational poverty in the ramshackle remains of coal towns; the healthcare industrial complex benefits from the uninsured and chronically ill; and fast-food chains create food deserts where healthy food is unreachable and unaffordable, Appalachia cannot begin to address its social problems which are, as I argued in my introduction, not local to the region, but are American problems. The convenience of Appalachia as a scapegoat for the right and the left can no longer continue, according to the claims of a queer Appalachian subjectivity. 
The space where the narrative ends releases its subjects into a positionality where physical, embodied change can be enacted. Charland argues that constitutive rhetoric "positions the reader towards political, social, and economic action in the material world" (141). Electric Dirt imbues Queer Appalachians with a history and a purpose, and they thereby can enact that subjectivity in the material world towards change. Although there is an idealized ending or a perfect resolution of working-class representation in arenas of power, reparations made to disenfranchised folx, and a breakdown of the class system that allows billionaires to profit from the labor and misery of workers, the rest of the narrative remains unwritten as of yet. For example, mutual aid is a collectivist, anticapitalist framework offered by the zine, but whether or not it is able to be carried out effectively is the job of the constituted audience. A Queer Appalachian subjectivity may dictate which presidential candidates are viable for the coalition in 2020, but the success of that constituted subjectivity is entirely dependent on the participatory audience. The following chapter argues that Electric Dirt's constitutive rhetoric has been successful, as seen through the constituted audience interacting with and participating on the @queerAppalachia social media account, which serves as an extension of the zine, its claims, and its constituted collective identity. 


\section{CHAPTER TWO: @QueerAppalachia}

@QueerAppalachia9's social media presence furthers the arguments and claims made by the work of the Electric Dirt zine (as seen in the previous chapter), sharing content with an audience of over 250 thousand followers. Electric Dirt created its narrative and constituted its audience through its solidified function as an artifact similar to the White Paper (see previous chapter) of the peuple Quebecois. That audience's engagement with the Instagram page, however, functions similarly — though not exactly - to the vote carried out during the 1980 Referendum regarding whether or not the peuple Quebecois should, in fact, possess their own country. This vote, though ultimately unsuccessful in fulfilling the goals of the $P Q$, legitimated the claims of the constitutive rhetoric of the White Paper and was a measure of its success. Where the function of @QueerAppalachia fundamentally differs from Electric Dirt is that the former's constitutive rhetoric must also be persuasive to be successful. This chapter articulates the areas of success and failure of the constitutive rhetoric created by Electric Dirt and carried on by @QueerAppalachia. Using Karen Kopelson's framework of constituting for the purpose of recruitment, I argue that @QA's constitutive rhetoric successfully recruits members within queer, progressive, working-class, and (sometimes) rural subjectivities by creating a collective identity that encompasses all of the above categories and unifies previous disparities between them, but that it fails to persuasively interpellate into this collective identity those who are not already members of one or more of these subjectivities. The

\footnotetext{
${ }^{9}$ When referring to the Instagram page, I will use@QueerAppalachia. When referring to the collective itself, I will use Queer Appalachia without the @ sign.
} 
ultimate goals of the collective are both to create a queer rural community and to achieve inclusion of that community in mainstream progressive narratives, and as this chapter exemplifies, the coalition's constitutive rhetoric is well poised to continue to work toward and potentially achieve these purposes in the future.

Electric Dirt established a history of queer and progressive folx in the Appalachian region, positioning this subjectivity toward political action. As the Editor-inChief, Gina Mamone, said, "it was clear within the first two weeks that we had more content that [sic] we knew what to do with. We just started posting it, turning our social media feeds into a constant in real time zine" (Lucid). As an "in real time zine," @QueerAppalachia has a massive reach, with over 250K followers and thousands of people engaging with every post. It is important to understand that the social media page functions as a far-reaching arm of the claims and collective in Electric Dirt, not as a separate entity or agenda. @QueerAppalachia reveals the ways that the successfully constituted audiences of Electric Dirt act out their positioning in the material world, which Charland's examines in his discussion of the effective power of constitutive rhetoric, stating:

this positioning of subjects as historical actors can be understood as a two-step process. First, audience members must be successfully interpellated; not all constitutive rhetorics succeed. Second, the tautological logic of constitutive rhetoric must necessitate action in the material world; constitutive rhetoric must require that its embodied subjects act freely in the social world to affirm their subject position" (141, emphasis mine).

This chapter works with both of Charland's points here, determining the success or 
failure of the constitutive rhetoric from Electric Dirt through examining the action taken in the material world through @QueerAppalachia's Instagram page and those who engage with its posts and express their shared subjectivity through their participation in the page's rhetoric. Though narrative continues to be an element in @QueerAppalachia's constitutive rhetoric, the analysis of a social media account necessitates another emphasis beyond the role of narrative. Charland states, "constitutive rhetorics...insert 'narratized' subjects-as-agents into the world” (143). The following analysis of @QueerAppalachia's rhetoric examines enacted positionality of these subjects-as-agents and how they work toward fulfilling the claims made by the constituted identity of Electric Dirt. In the following section, I examine the way constitutive rhetoric works within social media, particularly regarding elements specific to the genre such as hashtags, algorithms, and recommended content.

\section{Social Networking and Constitutive Rhetoric}

Though the Instagram page is meant to operate in a manner similar to the zine, it is still important to solidify the differences between the constitutive rhetoric's function on the social media page and Electric Dirt. Barbara Warnick and David S. Heineman, who extend Charland's analysis of constitutive rhetoric into the realm of social networking, argue that identity can be constituted through the use of social media, stating, "the idea that social networking is a tool that can be used to both construct and defer one's identity and subjectivity is significant when considering the experience of all forms of social media" (95). Though social networking is, as seen here, a potential tool for constructing identity, social media pages using constitutive rhetoric do operate slightly differently than a static artifact like Electric Dirt. Warnick and Heineman help elaborate this difference: 
identity formation online is not as totalizing an experience as identity formation offline, in the real world. Charland's peuple Quebecois lived their lives differently and took political action as the result of a constitutive identity. Most people who join an Internet discussion group under the guise that they are someone other than who they 'really' are do not usually change their normal, material practices in such drastic ways" (Warnick and Heineman 104).

Although Warnick and Heineman point out the potential duality of subjects interacting in a digital sphere, for a constitutive rhetoric to truly be successful, it must necessitate a change in behavior or beliefs in the real, material world. The actors interpellated by Electric Dirt who are thereby participating in@QueerAppalachia's rhetoric on social media must be — and, I argue, are - acting in accordance with their actual constituted subjectivity in the material world. Acting out of this subjectivity is evident in the comments on@QueerAppalachia's posts, where folx regularly share their own stories relating to the themes and issues presented by the page's rhetoric and engage with other members of the community to continually reaffirm their subjectivity.

Electric Dirt constituted an identity from narrative, positioning its subjects toward change in the material world, and @QueerAppalachia fleshes out this narrative while working to recruit additional subjects into its constituted identity. In Charland's original example of the $P Q$, this shift from narrative for constructing a people to constituting individuals into this identity persuasively can be seen through the 1980 vote for sovereignty, as the White Paper spelled out the narrative before the vote for sovereignty, the aim of which was to persuade French-Canadiens that "they, as an audience, were not really Canadians" (Charland 135). The vote was unsuccessful, as only $45 \%$ of Quebec 
residents voted for sovereignty, showing that the White Paper only constituted those who effectively saw themselves as Quebecois, an effect of constitutive rhetoric that Karen Kopelson discusses in her 2013 article, "Risky Appeals: Recruiting to the Environmental Breast Cancer Movement in the Age of 'Pink Fatigue."' In this article, Kopelson utilizes constitutive rhetoric to examine the way Breast Cancer Action (BCA) and Breast Cancer Fund (BCF), two environmental breast cancer organizations, worked to "recruit new audiences to their cause" via the rhetorical appeals on their websites (107). Kopelson specifically looks at who the organizations "[constitute] as recruitable" in the wake of new potential audiences after the fall of Komen, a well-known breast cancer charity, compelled people to search for new breast cancer organizations to support (122). Through this analysis, Kopelson advances a theory arguing that constitutive rhetoric works to constitute subjects as either recruitable or not, and therefore only interpellates those who are already sympathetic to the claims of the organization and need not be persuaded. Kopelson concludes that BCF was far more successful than BCA, stating, "I find $\mathrm{BCF}$ the organization far more likely to prevail in this respect because they actually make an effort to appeal to and recruit new audiences" (127), while BCA "constitutes as recruitable only those it does not really have to persuade" (126). Similarly, constituting as recruitable is how@QueerAppalachia worked to gather their audience; though their constitutive rhetoric successfully interpellated previously diverse identity characteristics into a single subjectivity, it has simultaneously failed (so far) to recruit individuals who were not already sympathetic to the cause of queer rural progressives. Warnick and Heinemann discuss this effect of constitutive rhetoric, stating, "a text can only be 'constitutive' when it is able to make sense within a community's already existing 
perception of the potential of its own discourse" (Warnick and Heineman 104).

Therefore, though @QueerAppalachia's constitutive rhetoric can be argued to be successful, it can only be so within the realm of its own created subjectivity. For example, this queer Appalachian subjectivity, while potentially very persuasive to those who voted for Donald Trump for reasons aligning with his pro-working-class rhetoric, cannot be resonant with those who voted for him due to social reasons such as his antiqueer stances and policies.

Though interpellation certainly takes place through social media, it functions slightly differently from how Charland theorized in 1987. Charland states, "interpellation occurs at the very moment one enters into a rhetorical situation, that is, as soon as an individual recognizes and acknowledges being addressed" (138). In order for the individual to acknowledge being addressed, however, the individual must have an "acceptance of an imputed self-understanding, which can form the basis for an appeal" (Charland 138). Because the use of hashtags and algorithms means that social media users tend to be recommended more of the same type of content that they already interact with, Charland's argument regarding interpellation takes on a new meaning when considering the nature of social media, as users are continually hailed into the identity they have already been constituted as, participating in "a rhetoric of socialization" and occasionally entering into digital echo chambers (Charland 138). For example, if a user continually interacts with queer content, rural content, or progressive content, they are more likely to be "recommended" posts from @QueerAppalachia, interpellating the user into this particular subjectivity through one or more of their materially enacted identity characteristics. Conversely, users who engage with conservative content are significantly 
less likely to see content from progressive creators.

Warnick and Heineman conceptualize social media's potential for constitutive rhetoric as a "metaperspective," stating, "a constitutive theory of identity goes beyond an analysis of those categories of identification provided on the site...but instead considers the ways in which participation in the site itself is a significant marker of cultural identity, shifting how we understand subjectivity more widely" (104). Through this understanding, it is evident that @QueerAppalachia's main audience is composed of those who identify with one or more of the subjectivities appealed to, and the very action of continuing to constitute this audience works to fulfill the claims of Electric Dirt, the primary goal of which is to argue for progressive rural folx' right to be heard and acknowledged. The obvious issue when examining Instagram in particular is that, though the possibilities of spreading a queer Appalachian subjectivity seem vast when considering the millions of individuals who use social media daily, potential for activism is limited to those who are already searching for and interacting with the type of content published by the collective. As I discuss in the next section, however, @QueerAppalachia's main claim is directed at establishment liberals, who, though likely not interacting with queer rural perspectives via social media, have, by virtue of the political action taken by the coalition, been exposed to the subjectivity of the collective and thereby its claims. Therefore, the rhetorical constitution of a queer Appalachian audience has been successful, as this coalition can now make claims and work to persuade an outside audience. The question this chapter aims to answer, then, is: does @QueerAppalachia persuasively constitute new recruits into the subjectivity created by Electric Dirt? 


\section{Constitutive Rhetoric in @QueerAppalachia}

As I discussed in chapter one, mainstream narratives about the region construct the major difference between Appalachia and the rest of the world as a politically right versus politically left split, but @QueerAppalachia, like the zine, continually reorients this split as a class-based conflict. In 2018, a Slate article celebrated the success of the coalition's progressive rural ideology, stating, “Queer Appalachia’s Mamone, Justin Sacco, Joey Aloi, and local artists released the 'Cornbread Communist Manifesto,' a 24-page zine cleverly trolling toxic tropes about hillbillies, advocating for laborers to unite within class across identities, and envisioning a radical redistribution of wealth centered on the rural poor" (Carey). Though it might appear that this class-based shift would recruit individuals who, regardless of political ideology, ${ }^{10}$ identify with anti-establishment, anticapitalist beliefs, this is not always the case, as even within "left-leaning" ideology, anticapitalist, anti-establishment rhetoric has been considered a radical viewpoint until recently. Much of @QueerAppalachia’s rhetoric, then, focuses on persuading and thereby recruiting those who are open to their cause; in the coalition's estimation, those with an establishment liberal ideology are the best target for persuasion, as this subjectivity is one that can be persuaded to acknowledge and attempt to fulfill the claims of the constituted subjectivity, despite the fact that "Queer people with blue-collar rural roots are noticeably absent from conversations and leadership in mainstream Democratic, progressive, and LGBTQ organizations around the country" (Carey). As Charland says, "identity defines

\footnotetext{
${ }^{10}$ Although I recognize that anti-establishment and anti-capitalist beliefs are inherently political, the state of politics in the US is intensely focused on "social and moral alignment" and/or "small versus big" government, so these deeper, more complex issues (the function/necessity of the establishment and the 'necessity' of capitalism in America) are taken as a given by both Republicans and Democrats. This topic could be a paper in itself, so I do not delve into it here.
} 
inherent motives and interests that a rhetoric can appeal to," meaning that establishment liberalism's motives of equality and rights for all are in line with at least some of @QueerAppalachia's beliefs and subjectivity, making them the perfect audience for persuasive recruitment.

One example of how already-interpellated rural progressive voices attempt to persuade and recruit liberal individuals is evident in the following photo from a 2017 @QueerAppalachia Instagram post (the photo featured in this post is depicted in figure 1). In the text below the meme, @QueerAppalachia directly addresses an establishment liberal audience, writing, "imagine being such a liberal elitist that you associate symbols of working class people with love for Donald Trump automatically and are shocked to find out that they don't fit your narrative... IMAGINE” (March 5, 2017). Rather than referencing Trump (or conservative viewpoints) as a legitimate symbol of the region, @QueerAppalachia argues against the mainstream narratives

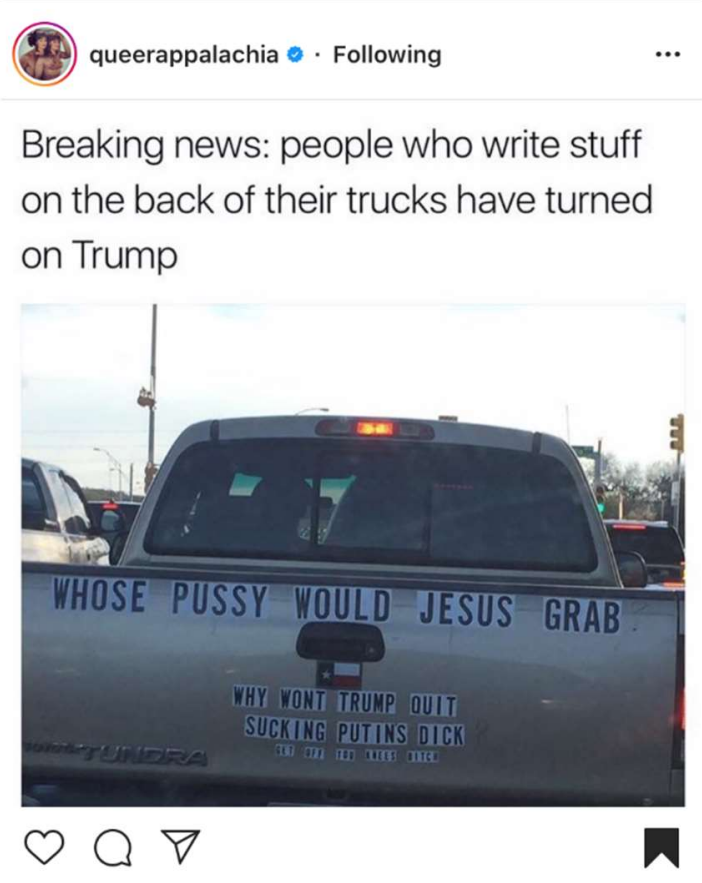

Figure 1 that construct working-class voters as conservative Trump supporters, using evidence of a working-class symbol—writing on the back of a pickup truck — and an anti-conservative, anti-Trump statement. As Charland argues, "the ultimate justification for...claims is the subject's character, nature, or essence," and @QueerAppalachia inverts expectations of Appalachian identity to make an argument based on a progressive working-class identity, 
both continuing to reconstruct Appalachian identity as essentially anti-capitalist while "calling out" the elitism of liberals who, though claiming to empower the disenfranchised, neglect—or refuse — to consider rural voices in Appalachian narratives. @QueerAppalachia invites identification from their audience through class issues such as access to healthcare. Identification is an important element of persuasion within constitutive rhetoric according to Warnick and Heineman, who state, "identification works through association: the rhetor attempts to associate some substantive part of himself or herself with the same part in the members of their audience" (98). Many of the Instagram posts about healthcare are for the purpose of inviting identification from @QueerAppalachia's audience; for example, in a post featuring a broken-off tooth lying on a wood table, @QueerAppalachia writes, "poverty and health issues are often blamed on a lack of morality or faith. There is not enough talk about class, ever...there will still be class markers like teeth that will always give you away." Later, the post argues, "reality is that tooth decay signifies poverty in harmful \& subtle ways. W/o [without] expanding insurance to cover oral health, millions of Americans will continue to live with pain, stigma, and the risks of systemic disease that could be averted through an accessible and integrated system of dental care" (@QueerAppalachia, March 8, 2020). Sharing a common experience of poor dental health prompts statements of identification from the comments. One example comes from user @busty_laroux, who writes, “I'm from a tiny town in SW VA, spent my whole life poor, and without dental insurance... at 37, my teeth are crumbling...they are showing their age, and their status" (Comment Section, March $8,2020)$. There are dozens of statements like these about dental issues as class discrimination in the comment section of this particular post. By asking the audience to 
identify with the issue of healthcare as a class struggle, @QueerAppalachia makes an argument for universal healthcare unattached to employment, which reorients the issue from a political clash to a class-based ideology. Progressive rural folx who identify with and bring awareness to the importance of this issue now have the potential to persuade and thereby recruit—if not the identities, at least the attention—of establishment liberals like Democratic presidential nominee Joe Biden, who currently does not support healthcare for all.

The explicit anti-capitalist messages of @QueerAppalachia are not the only examples of rhetoric that have the capacity to persuade and interpellate, however. As Leigh Ann Carey argues in her 2018 Slate article celebrating Queer Appalachia's leftist principles titled "Raise Hell and Eat Cornbread, Comrades!" she states:

In a moment of intense income inequality, a fierce critique of capitalism is needed, but a critique capable of knitting people together. The queer farmers, banjo players fighting fascism, and black lesbian rodeo stars - all living in the region and visually represented through Queer Appalachia's network-possess valuable translation skills. These folks, whose lives toggle between supposedly incongruent identities, effectively navigate within radical organizing spaces and conservative political and religious spaces."

The ability of queer Appalachians to navigate these diverse and oppositional locales is symptomatic of the success of their constituted identity. Is it possible, however, for Queer Appalachia's rhetoric to recruit those not already living with a queer or rural subjectivity through their constitutive rhetoric? Charland argues that existing subjectivities can be altered through the emergence of new subjectivities, stating, "various contradictory 
subject positions can simultaneously exist within a culture: we can live within many texts. These contradictions place a strain upon identification with a given subject position and render possible a subject's rearticulation" (Charland 142). "Hailing," in this context, refers to forcing tension into existing subject positions in order to interpellate individuals into a new subjectivity. One way this functions in my analysis would be that Appalachians who feel ashamed of their roots can be "hailed" into a recognition that this sense of shame comes from elitist, class-based conditioning, and they can thereby be recruited into a queer Appalachian subjectivity that unifies these warring factions of an individual's identity, bringing them into a collective. Conversely, @QueerAppalachia's content forces tension into the existing subjectivity of establishment liberals, suggesting that their elitism is class-based and is therefore rooted in prejudices that a liberal subjectivity should argue against. By introducing class-based claims, @QueerAppalachia again reorients the discussion away from a political right/left split, implicitly and explicitly arguing that simply being socially left is inadequate for addressing the issues present in the region and country as a whole.

An excellent example of explicating the difference between liberal and rural progressive subjectivities can be seen in a @QueerAppalachia post from July of 2020 (figure 2). The first image in this post features text stating, "You are not better than people in the south: a response to regional biases and 'liberal safe haven' elitism" (July 9, 2020). The ideas in this post reference the problematic notions of Appalachia as America's scapegoat that I referenced in chapter one of this project, but relay them in a palatable, easy to understand format for the purpose of persuasive interpellation, as although constituting an audience technically takes place before persuasion of that 
audience can occur, Kopelson argues that constitutive rhetoric can also work to persuade, and that in fact, intentionally working to persuade subjects to join a specific audience may lead to more successful constitution (Kopelson 126). The example of hailing in this post is particularly powerful; in the image pictured in figure two - the first slide to use a direct "you" statement—-the post directly addresses the viewer as someone participating in these negative perceptions and informs the audience that they are, in fact, responsible for the consequences of perpetuating these harmful stereotypes. Being hailed in this way necessitates interpellation into one of two subjectivities: either the audience is

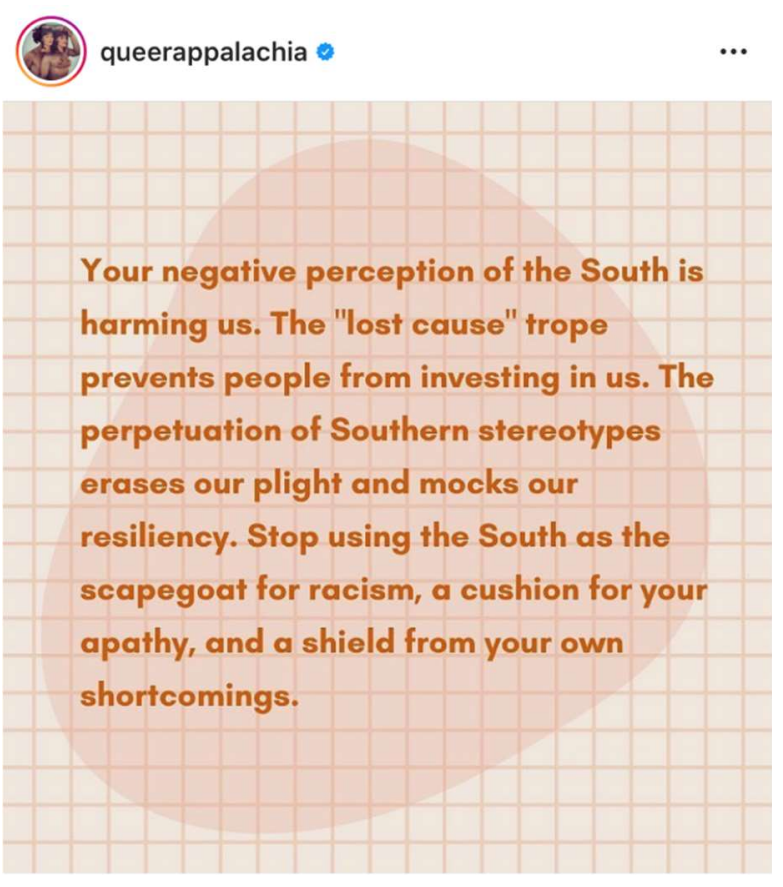

Figure 2 interpellated into a subjectivity sympathetic to and aligned with progressive rural queerness, or a subjectivity that embraces elitism, which is necessarily in incredible tension with an idealized version of leftist ideology that would not exclude people based on class distinction. Because elitism is an undesirable characteristic, the rhetoric works to recruit the "you" addressed in the post into the former subjectivity as an ally or member of the coalition. As discussed throughout this project, a key goal of rural progressive endeavors is to talk back against the placement of blame for the nation's problems on the shoulders of poor, working-class, rural people. This, in turn, opens the door for mainstream conversations about battling bigotry and inequity across the nation, rather than relying on a convenient regional "Other" that allows the rest of the 
country to ignore the problems inherent in the nation as a whole. Interpellating individuals into a sympathetic subjectivity through rhetoric such as that seen in this post works toward fulfilling these goals of visibility and progressive rural inclusion.

Also fundamental to @QueerAppalachia's claims and persuasive recruitment efforts is the concept of metronormativity, also known as "queer anti-urbanism ${ }^{11}$." The collective defined metronormativity as operating "upon the false dichotomy of rural vs. urban queer existence. It assumes that while the two existences differ from each other, there is no difference between queer life in different urban areas, nor any difference between queer life in different rural areas - since, according to metronormative queer society, rural queer life does not exist" (March 26, 2020). The term metronormativity is closely linkedwith@QueerAppalachia's conception of liberal elitism, as this post, while not specifically addressing individual queer folx in metro areas, does call out the wellknown organization GLAAD (Gay \& Lesbians Alliance Against Defamation), stating: we have seen [metronormativity] from the [GLAAD] recently, in their choice to give the Vanguard Award for making a significant difference in promoting equal rights for Queer people to Taylor Swift, despite her trainwreck of a music video "You Need to Calm Down". This video promoted metronormativity and conflated rural life with bigotry, nasty stereotypes about being ill-educated and poor, and being directly in opposition to Queer life."

Among recent mainstream liberal narratives, Taylor Swift has repeatedly been considered a staunch ally for queer people, despite the decidedly anti-rural propaganda in this video,

\footnotetext{
${ }^{11}$ Jack Halberstam first refers to this concept in his 2005 book In a Queer Time and Place: Transgender Bodies, Subcultural Lives, although the term was popularized by Scott Herring in his 2007 article "Out of the Closets, Into the Woods: RFD, Country Women, and the Post-Stonewall Emergence of Queer Antiurbanism" and 2010 book Another Country: Queer Anti-Urbanism.
} 
made doubly ironic by the fact that her career began with country music.

@QueerAppalachia's callout of both GLAAD and Taylor Swift puts the collective in opposition to mainstream narratives that so often worship celebrity and elitism and centers class, not political, conflict. The rhetoric of metronormativity undermines the potential for interpellation into a sympathetic subjectivity of allyship with queer rural folx; therefore, openly pushing back against a celebrity lauded for championing queer rights aims to once again force tension into an existing subjectivity, this time an urban queer one, in an effort to rearticulate members of this subjectivity into allyship with queer rural progressive folx.

Having exemplified how@QueerAppalachia reorients national conflicts as classbased issues, constituting elitism into a "common enemy" among working-class folx everywhere, I now move into an analysis of the success of this class-based rhetoric. There are multiple potentially recruitable audiences, especially when regarding the medium through which these arguments are conducted. First, there are subjects identified as queer, rural, and progressive already. Second, there are subjects supportive of establishment liberalism — which is, as I have endeavored to make clear in this chapter, related to, but different from progressive ideology. Third are subjects who voted for Donald Trump due to feeling rejected and unheard in politics and national matters because of being rural and working-class. While there are certainly individuals coming from other backgrounds and identities who may encounter the rhetorical addresses of @QueerAppalachia via social media—namely, those who supported Trump due to his extreme right-wing beliefs - these three subjectivities are the ones being hailed by the constitutive rhetoric of the Instagram page and are therefore primed for successful or 
unsuccessful recruitment.

\section{Success and Failure of Queer Appalachia's Rhetoric}

@QueerAppalachia and Electric Dirt's main goal is to recruit those who already identify as queer, rural, and progressive. This collective is primarily for folx who are doubly and triply disenfranchised by their subjectivities and is meant to provide a safe space and a coalition that provides mutual aid, harm reduction, and community for those without, particularly when due to these identities. The success of Electric Dirt's initial call for submissions and publication pays tribute to the success of this rhetoric in constituting an audience of queer, rural, progressive folx. The project raised over $\$ 70,000$ for Electric Dirt's first issue, and the number of received submissions in the first few weeks was "enough for a dozen zines" (Lucid). The zine itself has sold out, and the collective is now working on publishing volume two. Similarly, the Instagram page boasts over 270 thousand followers, with posts receiving thousands of "Likes" only hours after their publication. Queer rural folx detail their experiences in the comments of the posts and engage with each other, building a remarkably active digital community of those from the region. For these audience members, @QueerAppalachia also plays a role in providing assistance and education, offering harm reduction seminars for those struggling with addiction and promoting networking that allows for mutual aid in the form of finances, housing, medication, employment, and other grassroots action to help one disenfranchised individual at a time. Members of queer Appalachia lift one another up and support one another, and this can be seen over and over in the history of the posts made on the Instagram page. Furthermore, the collective offers grants for small businesses and other projects, working to combat "brain drain" in the region and uplift 
the region through bringing rural-owned industry to the region rather than relying on the exploitative existing infrastructure. Electric Dirt and @QueerAppalachia have successfully constituted this identity and recruited thousands of individuals to their queer, rural, working-class, anti-capitalist community working to better the lives of those in the region.

The second potential audience for interpellation is those who support establishment liberalism, and, though this ideology does not include anti-capitalism, an establishment liberal audience is directly addressed by @QueerAppalachia’s content, as I argued earlier. Due to the often divisive and derisive language leveled toward establishment liberal ideology, however, I believe that the success of @QueerAppalachia's rhetoric with this second audience is mixed. Much of @QueerAppalachia's content is educational, including the post I examined earlier addressing "Liberal Safe Haven" elitism, introducing and explicating concepts like metronormativity and elitism in order to persuade and thereby interpellate those who previously believed in the potential of establishment liberalism. The work that @QueerAppalachia does to reorient political issues back to issues of class appeals to those either coming from or sympathetic to a working-class background, successfully interpellating them into a subjectivity that addresses the class inequity present in the country and its problems. One example of how @QueerAppalachia constitutes progressive/liberal ideology as a class-based discussion is through the coalition's attack on RuPaul, a drag queen heralded as a hero by the liberal left for bringing drag and queer topics into the mainstream through their show RuPaul's Drag Race.@QueerAppalachia raises the issue of RuPaul leasing his land for the purpose of fracking, working to reveal 
the harm of capitalism enacted by this mainstream liberal icon. Part of the power of their attack is that the coalition is bringing attention to class-based issues by publicly condemning the actions of a well-known queer figure. On April 16, 2020, @Q QueerAppalachia posted an image featuring text reading "start your engines (on your slurry blender and fracturing pump," calling out RuPaul's involvement in fracking, a practice harmful to the environment conducted for the purpose of extracting fossil fuels. Fracking is an issue for Appalachia as evidenced by a rural Ohioan's testimony via a piece for the Guardian, arguing:

It can feel remote here to outsiders...I believe that's also what drew fracking companies here - fewer people to make a fuss, and the kind of people that others sometimes don't care about: the poor. I believe it is significant that states chose to bury their fracking waste in the hills of Appalachian Ohio, in a county with a median household income of $\$ 19,855$; it's hard to know what goes on in these hills. It's hard to see what's behind the trees" (Stine).

Fracking draws comparisons to the exploitation of coal mining in the region, for good reason. Though I cannot go into more detail on this practice for the purposes of this example, suffice it to say that this is an incredibly harmful capitalist exploitative practice. It is significant that @QueerAppalachia has posted two of the eight posts on Instagram hashtagged with \#RuPaulsfrackrace. As a queer platform, the coalition can educate their liberal audiences to show that being queer and being left does not provide an exemption from being part of the establishment that oppresses disenfranchised people, and that the slogan \#NoWarButClassWar applies to every issue.

@QueerAppalachia occasionally utilizes rhetoric pointing out differences rather 
than similarities, and although this is beneficial in unifying their specific community, it is unsuccessful in interpellating audience members who might have similar experiences in different locales. Much of @QueerAppalachia's post history is confrontational and even aggressive, operating from generational regional trauma stemming from being ignored in mainstream narratives and exploited by capitalists for decades. One example of this confrontational rhetoric can be seen in a post from December 20, 2019, featuring text reading "You were radicalized by Brooklyn podcasts; I was radicalized by my dad pullin his gun on the repo man; We aint the same." The text under this post states "Not tryin to talk about class w/ you if you never caught a shut off notice." This post is unique in that there was quite a bit of backlash in the comments, primarily from poor folx from New York neighborhoods who felt that this kind of "stratifying" was not beneficial to class unity. @QueerAppalachia responded by specifying the “Appalachian” portion of the page's goals, arguing that experiences of poverty in urban versus rural areas was fundamentally different. It is worth noting that there are significantly fewer instances of "Othering" rhetoric than there are of more successful, unifying, revolutionary rhetoric. Therefore, @QueerAppalachia is largely successful in recruiting audiences that may have been subjects of establishment liberalism through education, promoting class solidarity as the truest form of change, and relating experiences of poverty and class struggle.

The final potential audience for recruitment are those who voted for Trump due to class issues rather than political issues. There are two primary avenues of identification that would lead to potential interpellation; one, those who identify with notions of Appalachian fatalism either through observation or personal experience and therefore are motivated to reverse and combat it, as this fatalism not only results in thousands of folx 
in the region abstaining from voting, but also provided a foothold for Trump's rhetoric that appeared to listen to working-class voters in a way that Hillary Clinton did not. Two, one would be hard-pressed to find someone from the region who has not been affected by the opioid epidemic, and therefore the harm reduction work that the coalition does in the region has the potential to interpellate those struggling with addiction who might otherwise not have been receptive to @QueerAppalachia's message. Education about what Trump has truly done, as well as education about how and why some rural folx voted for him, is occasionally featured on the Instagram page. However, though the messages of anti-fatalism and harm reduction may resonate with a few individuals, as a whole, @QueerAppalachia does not aim their rhetoric toward recruiting those who have supported Trump for social reasons (though there is some room for accepting those who did support him previously due to his pro-working-class rhetoric). Opposing Trump represents a life and death struggle for rural queer folx, and so while it is certainly possible for their anti-fatalist and harm reductive messages to be heard, @QueerAppalachia aims to uplift voices and support progressive political candidates and messages.

With a message espousing optimism as a political action, @QueerAppalachia does not leave much room for those who do not believe in the possibility of the region to rise up and overcome its historical disenfranchisement. Instead, @QueerAppalachia, as Kopelson puts it, "constitutes as recruitable" those sympathetic to their cause, and though met with mixed success, it is undeniable that the coalition has played a significant role in bringing the identity and claims of rural queer folx to a mainstream audience (126). By directly addressing individuals, corporations, pundits, politicians, social media 
influencers, and all others who continue to perpetuate stereotypes that harm the region and the nation as a whole, @QueerAppalachia's rhetoric successfully interpellates those who have felt alienated by their identities and gives them a positionality through which to act in the material world. Other audiences are, through @QueerAppalachia's constitutive rhetoric, offered the opportunity to learn about the goals and claims of the coalition and thereby take part in bringing reparations and recovery to the region rather than perpetuating the harm done through capitalism and supporting exploitative capitalist practices, and even minimal success in this area is extremely significant for working to turn the tide of the region's health and prosperity.

\section{Conclusion}

Though @QueerAppalachia is not successful in all areas of potential interpellation, the coalition has undoubtedly constituted an audience that has great potential for making change in the material world. Through providing a community for anti-capitalist revolutionary queer folx, as well as persuading establishment liberals to the urgency of a class-based movement, @QueerAppalachia has almost unprecedented possibility for influence. In a region where groups often fizzle out after a short period of success, it is imperative that @QueerAppalachia continue to reinforce and support this community while interpellating new queer revolutionaries to their cause. The national conversations taking place in 2020 regarding racial injustice provide a - possibly unprecedentedhistorical opportunity for reorienting and interpellating individuals to anti-establishment causes.@QueerAppalachia has seized the moment and engaged in these conversations nationally and regionally, helping folx take a stand for Black Lives in their rural areas, continually presenting progressive rural identity to a mainstream audience in an effort to 
recruit to their cause. The success of the coalition's constitutive rhetoric speaks to the importance of including queer rural voices in national conversations, as these communities play an important role in shaping social movements and shedding light on the most disenfranchised members of our country. 


\section{CONCLUSION: PROGRESSIVE APPALACHIA IN THE WAKE OF MAMONE}

Scratch that; this is not a moment, it's the movement. - Hamilton: An American Musical

On August 3, 2020, the Washington Post published an article titled "The Tale of Queer Appalachia," with a subscript reading "a popular Instagram account raises funds for LGBTQ people in Appalachia. But does the money really go where it's supposed to?" The lengthy article lays out damning evidence with respect to the following key points: first, QA is not run by an intersectional collective, but rather Mamone and their (white) partner, the former of whom has a sketchy-at-best history with finances and organizations; second, Mamone is accused of misappropriating funds donated by subscribers and followers for regional aid; third, there are pieces of content shared on the Instagram page that were stolen by Mamone and are thereby exploitative, especially of people of color; fourth, there is a verified shameful history of racism, gatekeeping, and silencing behavior by Mamone and QA; fifth and finally, much of the above was known by other grassroots coalitions in the region who were afraid to speak out and stand up against QA for fear of retaliation. @QueerAppalachia (i.e., Mamone) published a retaliatory attack on Instagram against the author of the Washington Post piece in lieu of an apology or explanation, further angering and upsetting those in the progressive Appalachian community. While an opportunity for ousting Mamone and restructuring QA around queer POC leadership presented itself, other queer rural organizers (some of whom were interviewed for the Washington Post piece) claim that Mamone quickly 
regained control of all QA accounts, and @QueerAppalachia has not published anything since August 7, 2020. Unfortunately, the disruption, dissolution, and exposure of organizations in Appalachia is not uncommon, as the region has a lengthy history of short-lived grassroots movements that fall apart in time for one reason or another. Though this exposé on QA is heartbreaking and disheartening for many in the progressive Appalachian community, I exemplify in this conclusion that the audience and subsequent community recruited by Queer Appalachia does not rely on the continuance of Mamone's exploitative work to continue its goals. Furthermore, while the work of harm reduction and community building may have been brought to some mainstream audiences through QA's social media, the work was not started by Mamone and will not be ended by their discreditation. Organizations like Appalachian Feminist Coalition, Holler Health Justice, and Queer Kentucky have been doing this work for many years, and with the renewed support of QA's constituted audience in the wake of this disappointment, these coalitions will be funded and empowered to continue working in the region.

Queer Appalachia did the work of recruiting folx across the country—and indeed, across the world - into an ideology that recognized the inherent classism of America's failings, raising awareness about how that classism is intersectionally oppressive in conjunction with systemic racism and homophobia, and educating to show how this bigotry is conflated with and seemingly concentrated in specific regions. Queer Appalachia's - really, Mamone's - largest ideological failing, however, was in their inability to practice what they preached about radical anti-capitalism. In the aforementioned Washington Post exposé written by Emma Copley Eisenberg, Leo, a 
former associate and assistant of Mamone's, states, “"They presented themselves as a leftist and an anarchist... But at the end of the day, it's capitalism. And it's been exploitation of all these people who really believe [in] and maybe have projected what they've wanted onto this project'" (Eisenberg). Therefore, though I argued in Chapter 2 that the participants and audience of Queer Appalachia were acting in a transformative way in real life due to their engagement with Queer Appalachia, Mamone took advantage of the constituted QA audience for their own gain. The silver lining, however, is a key element of the community formed by this rhetoric: the coalition's content was, by and large, created by progressive Appalachians who shared their content via QA's platform, meaning that almost none of the original content was created by Mamone. As Warnick and Heinemann suggest, "social media facilitate collective authorship, suggesting that groups and collectives can create their own narratives collectively," (109). I argue that, despite Mamone's tarnishing of QA's reputation and personal misappropriation of funds, the audience was still constituted through the creation of a narrative and subsequent interpellation of subjects into that identity, as Charland conceptualizes through his examination of the peuple Quebecois and their white paper, which I discussed in Chapter 1. This community continues to exist in online spaces outside of @QueerAppalachia, doing the work that they were originally motivated to do through their initial interpellation. Many of the conversations in the comment sections of @QueerAppalachia's Instagram page exemplify this process of self-defining, particularly in an August 7 post, when user @amandaleilei stated, "for me repairing the space instead of abandoning feels important because this is a massive [space], that I believe can become a true movement launching point that has not, in my experience, existed for rural 
Appalachian queers before. And I want that space to exist and to build power for my community, the right way." On the same comment thread, another user, @dhpluta, concurs: "despite all the stuff that has gone down, we really cant [sic] ignore the good that QA has done for queers and QBIPOC in appalachia for representation. Without QA, to a certain extent appalachians would still be only be seen as hillbillies. We need to acknowledge the benefit they have provide [sic] while putting in the work to improve the bad stuff." These comments are, as of November 2020, no longer available, as Mamone has turned off the ability to comment on the top ten most recent existing posts from @QueerAppalachia. While some former supporters have continued to express their discontent and hurt in the comment sections that are available, most have taken the advice of queer BIPOC organizers in the region by following other queer Appalachian and Afrolachian accounts, supporting organizers on the ground in the region, working toward anti-capitalist goals, and excluding Mamone from the equation. Mamone, thankfully, did not stifle the voices, goals, or enthusiasm of the audience that was created on the QA online space and through Electric Dirt.

The epigraph from Hamilton conceptualizes how progressives in Appalachia can move forward in the wake of Mamone's betrayal. The @QueerAppalachia platform itself is, unfortunately, defunct. Mamone has hired legal counsel, refuses to respond to calls for transparency, retook the account after an attempt to rework the platform was made by Black queer organizers from the region, continues to refer to themself as "we," and states on the Queer Appalachia website, "We will not engage in a futile back and forth about our innerworkings and have our intentions questioned." Fortunately, this moment of manipulation, dishonesty, and thievery does not spell the end of the progressive 
Appalachian movement. Though Mamone exemplified the potential duality of social media engagement as conceptualized by Warnick and Heinemann, the actual queer rural BIPOC audience constituted by QA's rhetoric has allowed their interpellation to alter their everyday lives, working with harm reduction, coalition-building, and grassroots activism in the region. In lieu of supporting QA, this community has diversified to support organizations truly doing this work with Black queer folx on their leadership teams. These organizations include Appalachian Feminist Coalition, Holler Health Justice, Virginia Harm Reduction, Sexy Sex Ed, Out in Appalachia, Queer Life Appalachia, Black in Appalachia, Queer Kentucky, and dozens of others. The community created by @QueerAppalachia has put out a call for continuing the work begun by this coalition, showing the real-world impact of constituting a new audience that is positioned toward action in the material world. As I argued in Chapter 2, the constitution of subjects already sympathetic to the cause of queer rural progressive identity was, in fact, successful, and the intent of this coalition to continue working toward these material, real-world goals reveals the success of the constitutive rhetoric for these subjectivities. While Mamone has undoubtedly done a great deal of harm in the region, the rhetoric of those queer BIPOC Appalachians who created QA's content was always about constituting an intersectional collective of queer Appalachians, and these folkx have united in force as a community against all of the exploitative white supremacy that Mamone has shown. This queer Appalachian is optimistic about the future of progressive grassroots organizations; the downfall of Mamone is simply a bad moment in a movement that has so much left to do. 


\section{REFERENCES}

Anglin, Mary. “Aids in Appalachia: Medical Pathologies and the Problem of Identity." Journal of Appalachian Studies, vol. 3, no. 2, 1997, pp. 171187. JSTOR, www.jstor.org/stable/41446280.

Billings, Dwight B., et al. "From the Editors.” Journal of Appalachian Studies, vol. 10, no. 1/2, 2004, pp. 3-6. JSTOR, www.jstor.org/stable/41446603.

Black, Kate, and Marc A. Rhorer. "Out in the Mountains: Exploring Lesbian and Gay Lives.” Journal of the Appalachian Studies Association, vol. 7, 1995, pp. 1828. JSTOR, www.jstor.org/stable/41445676. Accessed 22 Jan. 2020.

Carey, Leigh Ann. "Want to Know Where Intersectional Queer Radicalism Is Thriving? Look to Appalachia.” Slate Magazine, 5 Nov. 2018, https://slate.com/humaninterest/2018/11/queer-appalachia-radical-politics-south.html.

Catte, Elizabeth. What You Are Getting Wrong About Appalachia. First ed., Belt Publishing, 2018.

Charland, Maurice. "Constitutive Rhetoric: The Case of the Peuple Québécois.” Quarterly Journal of Speech, vol. 73, no. 2, 1987, pp. 133-150., doi:10.1080/00335638709383799.

Eisenburg, Emma Copley. “A Popular Instagram Account Raises Funds for LGBTQ People in Appalachia. It's Not Clear Where Those Donations Go." Washington Post, https:/www.washingtonpost.com/magazine/2020/08/03/popular-instagramaccount-raises-funds-lgbtq-people-appalachia-its-not-clear-where-thosedonations-go/. Accessed 5 Nov. 2020.

“Far Away from Any Witnesses, My Small Town Is Being Poisoned by Fracking Waste." The Guardian. https://www.theguardian.com/us-news/2017/sep/21/appalachia- 
ohio-fracking-wells-toxic. Accessed 5 Nov. 2020.

Fisher, Steve, and Barbara Ellen Smith. "Internal Colony_Are You Sure? Defining, Theorizing, Organizing Appalachia.” Journal of Appalachian Studies, vol. 22, no. 1, 2016, pp. 45-50, doi:10.5406/jappastud.22.1.0045. JSTOR.

Garringer, Rachel. ““'Well, We're Fabulous and We're Appalachians, So We're Fabulachians": Country Queers in Central Appalachia." Southern Cultures, vol. 23 no. 1, 2017, p. 79-91. Project MUSE, doi:10.1353/scu.2017.0006.

Harkins, Anthony, and Meredith McCarroll, editors. Appalachian Reckoning: A Region Responds to Hillbilly Elegy. First ed., West Virginia University Press, 2019.

Hayslette, Sandra, et al. "From the Editors." Journal of Appalachian Studies, vol. 12, no. 1, 2006, pp. 3-6. JSTOR, www.jstor.org/stable/41446691.

House, Silas. "The Road Back: Appalachia as Internal Colony." Journal of Appalachian Studies, vol. 22, no. 1, 2016, pp. 65-68, doi:10.5406/jappastud.22.1.0065. JSTOR.

House, Silas. "Our Secret Places in the Waiting World: or, A Conscious Heart, Continued." Journal of Appalachian Studies, vol. 20, no. 2, 2014, pp. $103-$ 121. JSTOR, www.jstor.org/stable/10.5406/jappastud.20.2.0103. Accessed 22 Jan. 2020.

Keith, Emily Anna. How a Queer Instagram Is Helping Fight the Opioid Epidemic in Appalachia. July 2019.

Kopelson, Karen. "Risky Appeals: Recruiting to the Environmental Breast Cancer Movement in the Age of 'Pink Fatigue."' Rhetoric Society Quarterly, vol. 43, no. 2, 2013, pp. 107-133., doi:10.1080/02773945.2013.768350. 
Lucid, Tamra. "Electric Dirt Zine and the Queer Appalachia Collective: An Interview with Mamone." Reality Sandwich, 7 Mar. 2017, https://realitysandwich.com/321487/electric-dirt-zine-and-the-queer-appalachiacollective-an-interview-with-mamone/.

Mann, Jeff. “Risk, Religion, and Invisibility.” Journal of Appalachian Studies, vol. 20, no. 2, 2014, pp. 124-131. JSTOR, www.jstor.org/stable/10.5406/jappastud.20.2.0124. Accessed 22 Jan. 2020.

Mann, Jeff. "Stonewall and Matewan: Some Thoughts on Gay Life in Appalachia." Journal of Appalachian Studies, vol. 5, no. 2, 1999, pp. 207214. JSTOR, www.jstor.org/stable/41446914.

Pendarvis, Edwina, et al. "From the Editors." Journal of Appalachian Studies, vol. 14, no. 1/2, 2008, pp. 3-6. JSTOR, www.jstor.org/stable/41446797.

“Queer Appalachia: Home.” QueerAppalachia, https://www.queerappalachia.com. Accessed 5 Nov. 2020.

Queer Appalachia (Project). Electric Dirt: A Celebration of Queer Voices and Identities from Appalachia and the South. Bluefield, WV : Queer Appalachia, [2017]-, 2017.

Ross, Katy A. “At the Intersection of Queer and Appalachia(n): Negotiating Identity and Social Support." OhioLINK Electronic Theses and Dissertation Center. Ohio University, 2019.

Smith, Barbara Ellen. "De-Gradations of Whiteness: Appalachia and the Complexities of Race.” Journal of Appalachian Studies, vol. 10, no. 1/2, 2004, pp. 38-57. JSTOR, www.jstor.org/stable/41446605. 
Vance, J. D. Hillbilly Elegy : A Memoir of a Family and Culture in Crisis. First ed., Harper, an Imprint of HarperCollinsPublishers, 2016.

"Violence Against the Transgender Community in 2020." HRC, https://www.hrc.org/resources/violence-against-the-trans-and-gender-nonconforming-community-in-2020. Accessed 5 Nov. 2020.

Warnick, Barbara, and David Heineman. Rhetoric Online: The Politics of New Media. 2nd ed., Peter Lang, 2012. 


\section{CURRICULUM VITA}

Brooke E. Boling

Graduate Teaching Assistant / University of Cincinnati / Department of English 5144 Rapid Run Road / Cincinnati OH 45238

bolingbe@ucmail.uc.edu / 502-386-5607

\section{Area(s) of Interest}

Social Movement Rhetoric, Queer Theory, Composition Pedagogy, Appalachian Rhetorics, Literacy Studies

\section{Education}

M.A. in English - University of Louisville, August 2018 - Present

Thesis: "'Don't Put an or Where God Puts an And:' Constitutive

Rhetoric in Queer Appalachia"

Committee: Drs. Karen Kopelson, Amy Clukey, and Catherine Fosl

B.S. in English - Johnson University, May 2018

Thesis: "Reclaiming Jane Rochester"

Thesis Advisor: Dr. April Kilinski

Academic Employment

Graduate Assistant, University of Cincinnati, August 2020 - Present

Reading and Writing Teacher, Institute of Reading Development, May 2019 - October 2019; May 2020 - August 2020

Graduate Teaching Assistant, University of Louisville, August 2018 - May 2020

Writing Center Consultant, University of Louisville, August 2018 - August 2019

Academic Support Center Tutor, Johnson University, August 2017 - May 2018

English Teaching Assistant, Johnson University, August 2015 - May 2018

Courses Taught

ENGL 101-04: Introduction to College Writing 
ENGL 101-86: Introduction to College Writing

ENGL 102-02: Intermediate College Writing

ENGL 102-06: Intermediate College Writing

ENGL 1001-003: Introduction to College Writing

\section{Publications}

“Searching for Purpose: Silas House's The Coal Tattoo" Papers \& Publications:

Interdisciplinary Journal of Undergraduate Research, Volume 7 (2018).

\section{Internships}

Miracle Monocle: Online Literary Journal, Editor \& Podcast Host, January 2019 May 2019

\section{Conference Presentations}

"Searching for Purpose: Silas House's The Coal Tattoo" South Atlantic Modern Language Association. November 2017.

"Holler Health Justice: Health Activism in Appalachia" Women, Peace, and Security Conference. Binghamton University. April 2020.

Honors and Awards

Outstanding English Major, Johnson University, May 2018

Graduate Teaching Assistantship, University of Louisville, Fall 2018 - Spring 2020

Graduate Assistantship, University of Cincinnati, Fall 2020 - Present

\section{Editorial Publications}

Queer, Rural, American: A Miracle Monocle Micro-Anthology. Graduate Editor. Fall 2019

Miracle Monocle: Issue XII. Graduate Editor. Spring 2019

Miracle Monocle Podcast. Co-Creator and Co-Host. Spring 2019

Affiliations

Appalachian Studies Association 